\title{
Employment Turnover and the Public Allocation of Unemployment Insurance*
}

\author{
John Hassler ${ }^{\dagger} \quad$ José V. Rodríguez Mora M $^{\ddagger}$ \\ Keywords: Unemployment insurance, voting, employment turnover. \\ JEL classification number: D72, J6, J65. \\ This version: October 1997
}

\begin{abstract}
Two features distinguish the European and the U.S. labor markets. First, European countries have considerably more generous unemployment insurances. Second, the duration of unemployment and employment spells are substantially longer in Europe - turnover is low. We will build a model of political determination of the unemployment insurance to explain these differences. We show that saving and borrowing is a good substitute for unemployment insurance when turnover is high, as in the U.S. A small deviation from actuarial fairness in the unemployment insurance system will then cause the employed median voter to prefer low unemployment insurance. With a low turnover, a high unemployment insurance becomes considerably more valuable to the median voter. Low turnover also causes a strong divergence between the longand short-run interest of the employed. If the median voter cannot bind future voters to a certain level of insurance, the voting cycle must be long to support a high level of insurance.
\end{abstract}

* We thank Antonio Cabrales, Assar Lindbeck, Torsten Persson, Kjetil Storesletten and Fabrizio Zilibotti for helpful comments and discussions. Christina Lönnblad provided valuable editorial assistance. All remaining errors are our own responsibility.

$\dagger \quad$ Institute for International Economic Studies, Stockholm University, S-106 91 Stockholm, Sweden. Email: John.Hassler@iies.su.se. Telephone: +46-8-162070. John Hassler thanks the people at the Minneapolis Federal Reserve Bank for their hospitality.

$\ddagger$ Department of Economics, Universitat Pompeu Fabra, Ramón Trías Fargas 25-27, 08005 Barcelona, Spain. Email: sevimora@upf.es. Telephone: +34-3-5421755. JVRM thanks the people at the Institute for International Economic Studies for their hospitality. 


\section{Introduction}

In this paper, we build a model of political determination of the level of unemployment insurance. The analysis will share many features of the influential paper by Wright [7]. Like him, we will disregard any incentive effects of unemployment insurance as well as other problems related to imperfect information. The rate of unemployment insurance will be determined by the preferences of a median voter. We will focus on the case when all individuals are ex-ante identical. There will, however, be two major differences between our and Wright's work. The first concerns the completeness of the capital market. The previously analyzed cases are the two polar opposites - no credit market market at all, i.e., no saving and borrowing and a complete market including private unemployment insurance. We analyze the intermediate case by assuming that individuals can borrow and save but not privately insure against the unemployment risk. The second major difference is that we relax the assumption that the median voter can fix the unemployment insurance forever. Instead we assume that votes on the level of insurance are taken periodically and current voters cannot bind future voters. We will show that both these different assumptions, in addition to being realistic, are fundamental to our results.

The empirical motivation for our analysis is that the generosity of the unemployment insurance varies substantially between countries. In particular, the unemployment insurance is much more generous in most European countries than in the U.S. This is reflected both in replacement ratios and the length of time an unemployed is entitled to benefits. ${ }^{1}$

A second difference between the labor markets in Europe and the U.S. is that the average flows in and out of unemployment are much higher in the the U.S. than in Europe - employment turnover is higher in the U.S. ${ }^{2}$ Table 1 shows the flow into and out of from unemployment in 1985 and $1993 .^{3}$ The flows are expressed as the percentage of employed (unemployed) who became unemployed (employed) in an average month of the corresponding year. In Germany, for example, only .25\% of the employed became unemployed an average month in 1985. The figure for the U.S. was about 10 times higher. Similarly, $6.1 \%$ of the unemployed found employment each month while the percentage in the U.S. was almost seven times higher. ${ }^{4}$ The low flow out of employment means that

\footnotetext{
${ }^{1}$ The OECD Job Study [8] computes an index of how generous are in OECD countries. According to this index, the system in Denmark and the Netherlands are the most generous, while the systems in the U.S. and Japan are the least generous. Due to multidimensional differences in the structures of the systems, any ranking can, of course, be ambiguous. However, it seems rather clear that most European countries have a more generous unemployment insurance than the U.S.

${ }^{2}$ We use the word turnover to denote the flow rates into and out of unemployment. This should be distinguished from job rotation which is typically used for flows on the labor market including flows of employed from one job to another. The level of job rotation defined in this way differs very little between the U.S. and Europe. (See, for example, Bertola and Rogersson [2] for a model of job-to-job rotation). In an analysis of unemployment insurance, the flows into and out of unemployment seems to be the main object of interest.

${ }^{3}$ There is, of course, also substantial variation in the flow rates over age groups and industries. Disaggregating over age groups and industries, the higher turnover in the U.S. seems to prevail, however. See OECD Employment Outlook [8].

${ }^{4}$ Note, however, the large flows out of unemployment in Finland and Sweden. This may reflect the
} 


\begin{tabular}{lllll}
\hline \hline & $\begin{array}{l}\text { Inflow * } \\
\mathbf{1 9 8 5}\end{array}$ & $\mathbf{1 9 9 3}$ & $\mathbf{1 9 8 5}$ & $\mathbf{1 9 9 3}$ \\
\hline Belgium & 0.14 & 0.42 & 2.7 & 8.6 \\
Denmark & 0.29 & 1.75 & 6.3 & 21.4 \\
Finland & 1.49 & 2.83 & 36.5 & 13.9 \\
France & 0.32 & 0.34 & 3.7 & 3.0 \\
Germany & 0.25 & 0.57 & 6.1 & 9.0 \\
Italy & 0.14 & 0.41 & 1.8 & 9.5 \\
Netherlands & 0.28 & 0.24 & 6.8 & 6.4 \\
Spain & 0.35 & 0.56 & 1.7 & 1.8 \\
Sweden & 0.66 & 1.25 & 28.5 & 11.6 \\
U.K. & 0.51 & 0.67 & 6.1 & 9.3 \\
\hline Average of above & 0.44 & 0.90 & 10.0 & 8.45 \\
USA & 2.45 & 2.06 & 41.4 & 37.4 \\
\hline \hline
\end{tabular}

* As \% per month of source population.

Source: OECD Employment Outlook, July 1995.

Table 1: Flows In and Out of Unemployment 1985

the average risk of loosing a job is low in Europe while high in the U.S. But then, why do we observe very comprehensive unemployment insurance systems in Europe while not in the U.S.?

Our analysis will focus on two questions. First, does a low employment turnover mean that the employed would prefer a high unemployment insurance, financed through taxes on the employed? Second, if people vote sequentially on the level of unemployment benefits, is it possible to sustain a high insurance equilibrium in a voting equilibrium?

In answer to the first question, we first demonstrate the importance of recognizing that in real life individuals can self-insure, i.e., they can substitute saving and borrowing for unemployment insurance. To illustrate the importance of this, we start with a simple search model without saving. We show that such a model implies that the willingness of an employed person to pay for unemployment insurance increases in the flow rates into and out of unemployment. That is, large flows between unemployment and employment, as in the the U.S., would tend to increase the level of insurance preferred by employed individuals.

We will see that this result is based on the assumption that individuals consume their wage when employed and cannot borrow when unemployed. If we allow the individuals to use a credit market to save or borrow, the result may be turned upside down. To understand this, we must realize that in absence of a credit market, the unemployment insurance serves two functions - to smooth income and to insurance against uncertain income shocks. Introducing a credit market means that individuals get another instrument at their disposal. However, the degree of substitutability between these two instruments

(unsustainably) low unemployment rates in these countries in 1985. For Sweden, much of the flow may have been to different unemployment programs where individuals are not considered as openly unemployed. By 1993, the outflow in Finland had fallen to 13.9 and in Sweden to 11.6. 
depends on the rate of turnover. Low turnover means that income shocks associated with unemployment are more persistent than when turnover is high. Highly persistent shocks imply that uncertainty over long horizons is high, which strengthens the insurance motive. On the other hand, with low persistence the problem is rather to smooth income between short but frequent unemployment and employment periods, which can be done effectively by saving and borrowing. Consequently saving is a good substitute for unemployment insurance when turnover is high, but much worse when it is low. ${ }^{5}$ This establishes a motive for the employed to introduce generous unemployment benefits when employment turnover is low.

In order to address the second question, we relax the assumption that the employed can fix the insurance level forever. Instead we assume that a vote is taken with regular intervals. The median voter can then only choose the level of insurance until the next vote, not forever. With low turnover, insurance is mainly important in the long-run, because in the short-run the employed can be relatively sure of keeping her job. But if the periods between votes are short, the median voter can only influence the insurance level in the short term. During this period, she will very likely not be much concerned about insurance. Since the median voter must bear the cost of the insurance herself, she will thus vote for low insurance or no insurance at all. We show that the voting cycle may have to be very long for the sequential voting outcome to be close to the permanent insurance case.

In a low turnover economy, everybody would benefit from a high insurance level. As we will see, however, the tension between the short-run good and the long-run best becomes more severe in a low turnover economy, so that the long-run best is more difficult to achieve. Boadway and Wildasin [1] discuss pension systems and state that, if voters do not expect their own votes to affect the votes of future voters, young non-altruistic voters will not vote for high pensions financed by high taxes on labor if the period until next vote is short compared to the period remaining before their retirement. A similar mechanism is at work here.

The paper is organized in the following way. In section 2 we construct the basic model we will use in the paper. In subsection 2.1 the individuals are not allowed to save and borrow. This assumption is relaxed in subsection 2.2. In section 3, we analyze the effects of introducing sequential voting and section 4 concludes.

\section{Preferences for Unemployment Insurance}

\subsection{A flow Model Without Savings}

Consider the following discrete time search model. Individuals receive a net income of $w_{e}$ when employed. When unemployed, they receive unemployment benefits, denoted $w_{u}$. If the individual is employed, there is an exogenous probability $q$ that she will

\footnotetext{
${ }^{5}$ Gruber [3] analyzes the consumption smoothing effect of unemployment insurance.
} 
become unemployed between the current and the next period. We call this probability the separation rate. Similarly, an unemployed individual may become employed the next period with the exogenous probability $h$, called the hiring rate. The only state variable for the individual is the employment status $l$ that can take the values $e$ and $u$, denoting employed and unemployed.

The value function for the median voter must satisfy

$$
\begin{aligned}
& V(e)=U\left(w_{e}\right)+\frac{1}{1+r}((1-q) V(e)+q V(u)) \\
& V(u)=U\left(w_{u}\right)+\frac{1}{1+r}((1-h) V(u)+h V(e))
\end{aligned}
$$

where $U(\cdot)$ is the per period utility function and $r$ is the subjective discount rate. It the follows that the expected utility in the two states is given by

$$
\begin{aligned}
V(e) & =\frac{(1+r)(r+h) U\left(w_{e}\right)+q U\left(w_{u}\right)}{r(r+h+q)} \\
V(u) & =\frac{(1+r)(r+q) U\left(w_{u}\right)+h U\left(w_{e}\right)}{r(r+h+q)}
\end{aligned}
$$

After substituting the CARA utility function $-e^{-\gamma c}$ for $U(\cdot)$, we can use the value function to study individual preferences over the level of an unemployment insurance that is financed by a non-negative pay-roll tax $\tau$. Income when employed is $w_{e}=w(1-\tau)$ where $w$ is the gross wage. Let $d$ denote the steady state dependency ratio, i.e., the ratio of the number of unemployed to the number of employed. Note that $d=q / h$. Let us now make the following definition.

Definition 1 The unemployment insurance system is actuarially fair if $w_{u}=w \tau / d$.

Note that if individuals have different separation and hiring rates, actuarial fairness for a particular individual should be calculated using her own separation and hiring rates.

Now let $a$ denoted the deviation from actuarial fairness in the system. We define $a$ from the following relation

$$
a=1-\frac{w_{u}}{w \tau / d}
$$

A non-zero $a$, i.e., a deviation from actuarial fairness, can arise for several reasons. One obvious reason is administration costs. Another reason is that differences in unemployment rates among individuals is less than fully reflected in different tax rates and/or benefits. Assume, for example, that the insurance system operates under a balanced budget and that all individuals face the same tax rate and the same unemployment benefits. Furthermore, assume that individuals belong to different types, denoted $i$, each with a 
particular dependency ratio $d_{i}$. It is then straightforward to show that

$$
a=1-d_{i} / d
$$

where $d$ is the aggregate dependency ratio, i.e., the economy-wide ratio of unemployed to employed. We will focus on the cases when $1>a \geq 0$ under the maintained assumption that the median voter faces a long run unemployment risk that is no larger than the aggregate unemployment rate. We assume that the median voter is employed and we will thus concentrate on her preferences over $\tau^{6}$.

Since $l$ is the only state variable, the preferred level of $\tau$ is fully determined by the median voter's employment status. To find that tax level we maximize $V(e)$ with respect to $\tau$. The first order condition for a maximum is

$$
\tau=\frac{d}{1-a+d}\left[1+\frac{1}{\gamma w} \ln \left(\frac{q(1-a)}{(1+r)(d r+q)}\right)\right]
$$

Note that with no deviation from actuarial fairness, the most preferred tax rate is

$$
\frac{d}{1+d}\left[1+\frac{1}{\gamma w} \ln \left(\frac{q}{(1+r)(d r+q)}\right)\right] .
$$

The first term, $\frac{d}{1+d}$, corresponds to full insurance. The second term in brackets is negative provided that the discount rate is strictly positive, which then implies less than full insurance. This result was established by Wright [7]. Now let us consider how the median voter's preferences change with turnover.

Result 1 The most preferred insurance level (strictly) increases in turnover when individuals do not have access to capital markets for borrowing and saving and discounting is (strictly) positive.

Proof: The derivative of (5) with respect to the separation rate, holding $q / h$ constant at $d$ can be written

$$
\frac{r d^{2}}{\gamma q w(1-a+d)(r d+q)}>0
$$

With strictly positive discounting, full insurance is suboptimal because increasing risk only has second order negative effects when moving from full insurance. On the other hand, the reduced tax gives more money to spend today while the loss comes in the

\footnotetext{
${ }^{6}$ At present, we analyze the welfare of the employed for different $\tau$ given that it is held constant for ever. The value of a constant $\tau$ that maximizes the value function of the currently employed may, however, not be attainable in a political equilibrium with finite voting cycles. We will return to this issue in section 3.
} 
future and is thus valued lower. This has positive first order effects on the value function of the employed. This latter effect is stronger when separation rate are low, since the unemployment period is expected to be further in the future. This is the intuition behind result 1 .

\subsection{Allowing Savings}

Now assume that the individuals can save and borrow but not privately insure against the employment risk. They receive an interest rate on their financial assets, denoted $A_{t}$, and the interest rate is, for simplicity, assumed to coincide with their subjective discount rate $r$. In addition to the employment status $l$, the amount of financial assets now also enters as an argument of the value function. The finite horizon value functions are given by

$$
\begin{aligned}
& V_{t}\left(A_{t}, l_{t}\right)=\max _{c_{s}} E_{t} \sum_{s=t}^{T}(1+r)^{-s+t} e^{-\gamma c_{t}} \\
& \text { s.t. }\left\{\begin{array}{l}
A_{t+1}=(1+r)\left(A_{t}+w_{t}-c_{t}\right), \\
A_{t} \text { given, } \\
A_{T+1} \geq 0 .
\end{array}\right.
\end{aligned}
$$

with

$$
\begin{gathered}
w_{t}=\left\{\begin{array}{c}
w(1-\tau) \text { if } l_{t}=e \text { (employed) } \\
\frac{w \tau(1-a)}{d} \text { if } l_{t}=u \text { (unemployed) }
\end{array}\right. \\
l_{t+1}=\left\{\begin{array}{l}
e \text { with probability }(1-q) \text { if } l_{t}=e \\
u \text { with probability } q \text { if } l_{t}=e \\
u \text { with probability }(1-u) \text { if } l_{t}=u \\
e \text { with probability } h \text { if } l_{t}=u
\end{array}\right.
\end{gathered}
$$

In appendix A.1, we show that as the horizon $T$ goes to infinity, the value functions converge to

$$
\begin{aligned}
V\left(A_{t}, e\right) & =-\frac{1+r}{r} e^{-\gamma\left(\frac{r}{1+r} A_{t}+c_{e}\right)} \\
V\left(A_{t}, u\right) & =-\frac{1+r}{r} e^{-\gamma\left(\frac{r}{1+r} A_{t}+c_{u}\right)}
\end{aligned}
$$

where $c_{e}$ and $c_{u}$ are constants determined from the first order condition of the Bellman equation. We also show that consumption equals the annuity value of financial assets plus 


\begin{tabular}{ll}
\hline \hline period & 1 month \\
$r$ & $3 \%$ per year \\
$\gamma$ & 2 \\
$w$ & 1 \\
$h_{\text {low }}$ & $1 / 18$ per month \\
$h_{\text {high }}$ & $1 / 6$ per month \\
$d$ & $10 \%$ \\
$q_{\text {low }}$ & $h_{\text {low }} / 10$ \\
$q_{\text {high }}$ & $h_{\text {high }} / 10$ \\
$a$ & 0 and $3 \%$ \\
\hline \hline
\end{tabular}

Table 2: Parameters

a constant that depends on the current employment status, i.e.,

$$
c_{t}=\left\{\begin{array}{l}
\frac{r}{1+r} A_{t}+c_{e}, \text { if employed } \\
\frac{r}{1+r} A_{t}+c_{u}, \text { if unemployed }
\end{array}\right.
$$

In appendix A.2 we show that there is always a unique solution to the maximization problem. Additionally we show that the constants in (11) satisfy

$$
w(1-\tau)>c_{e}>c_{u}>\frac{w \tau(1-a)}{d}
$$

which implies that the individual saves when employed and dissaves when unemployed.

An important feature of the value functions is that wealth only enters through the multiplicative term $e^{-\gamma \frac{r}{1+r} A_{t}}$. We can then define

$$
V(l) \equiv V\left(A_{t}, l\right) e^{\gamma \frac{r}{1+r} A_{t}} ; \quad l= \begin{cases}e & \text { if employed } \\ u & \text { if unemployed }\end{cases}
$$

Clearly, we can then use $V(l)$ to find individual preferences over different values of $\tau$. Since $V(l)$ is independent of $A_{t}$, preferences over different values of $\tau$ are also independent of $A_{t}{ }^{7}$

Let us consider a numerical example to illustrate the analysis. We use the parameter values from Table 2. In the upper panel of Figure 1, we plot the expected utility of an employed individual for different values of the replacement ratio, i.e., the ratio of unemployment benefits to net wages, when $a$, the deviation from actuarial fairness, is zero. $^{8}$ In the high turnover case, the hiring rate $h$ is such that the expected length of the unemployment period is 6 months. ${ }^{9}$ In the low turnover case the duration is 18 months.

\footnotetext{
${ }^{7}$ This, of course, results from using the constant absolute risk aversion function in conjunction with a risk level of constant absolute size.

${ }^{8}$ As seen from the expression for the value functions, $V(e)$ and $V(u)$ are monotone transformations of $c_{e}$ and $c_{u}$ so we plot the latter as functions of the replacement ratio.

${ }^{9}$ We use continuous time for convenience when calculating the expected value and variance of the
} 
The separation rates are proportional to the hiring rates, so that the dependency ratio is $10 \%$ in both cases. We see that the values of the replacement ratios maximizing utility of the employed approximately coincide. The maximum is achieved at an unemployment compensation of $69 \%$ and $66 \%$ of the net wage for low and high turnover respectively. The value functions are single peaked in the figure. In result 4 below, we will demonstrate that this is a general property of the value functions for employed and unemployed. This makes it possible to identify a median voter also in the case of ex-ante heterogeneity with respect to turnover and actuarial fairness.

Figure 1: Value functions of employed

There is, however, an important difference between the two curves - the curve in the high turnover case is much flatter. This implies that the value of the insurance (i.e., the utility loss of moving from optimal to no unemployment insurance) is smaller in the high turnover case. This implies that a small deviation from actuarial fairness affects the preferred insurance level more, the higher the turnover is. This is illustrated in the lower panel of the figure, where we have calculated the expected utility for the two cases, now setting $a$ equal to $3 \%$. In the high turnover case, we get a considerable reduction in the most preferred unemployment compensation, which now becomes as low as $3 \%$. With a slightly larger deviation from actuarial fairness, the most preferred level falls to zero. The effect is much smaller when turnover is low. The most preferred unemployment compensation then falls to $48 \%$.

So why is insurance then more important in the low turnover case? An intuitive explanation is that low turnover means that the income shock associated with a job loss is more persistent than with high turnover. It is well known that saving and borrowing is a good substitute for insurance when shocks have low persistence. Note also that the variance of the length of unemployment spells equals $\frac{1}{h^{2}}$ and thus increases with the expected length of the unemployment period. Due to the law of large numbers, an individual expecting to see many spells of unemployment/employment during some given horizon faces less uncertainty than an individual with few but longer spells of unemployment. With high turnover, the individual's problem is largely to translate her variable income into a smooth consumption stream. This can be done by the insurance system but almost equally well by saving and using the credit market. A small deviation from actuarially fairness makes the capital market preferable. With low turnover on the labor market, the opposite is true. Insurance is then important since one unusually long unemployment spell, with large effects on lifetime utility, is much more likely to occur. For example, the probability that someone who currently is unemployed has to wait more than three years before becoming employed is $13.5 \%$ in the low turnover case but only $0.2 \%$ in the high turnover. The probabilities of more than five years of unemployment are $3.6 \%$ and $0.005 \%$ respectively.

unemployment period. 
Now let us consider how the most preferred tax and insurance rates vary with employment turnover. The following two results show that this cannot be a monotonic relation.

Result 2 If turnover is zero, the value of unemployment insurance maximizing the utility of the employed workers is zero.

Proof: This is obvious, since the net wage decreases with the level of insurance in all future states of the world if turnover is zero.

Result 3 As turnover with a given level of unemployment increases to infinity, the value of the unemployment insurance maximizing the utility of employed workers converges to zero when savings are allowed.

Proof: In appendix A.3.

The intuition is the following. As turnover goes to infinity, the current employment status becomes irrelevant for the individuals permanent income. Consumption then becomes independent of the employment status when consumers have access to a capital market for consumption smoothing. The value functions in the two states thus converge. Insurance is then of no value. This is certainly not the case when no capital market exists, since consumption in the two states by assumption differs in this case when unemployment insurance is imperfect.

We now know that the tax level an employed voter would prefer most is zero both when the turnover is zero and when it is very high. Both common sense and our previous simulations indicate that there are parameter levels for which the most preferred tax rate is positive. The following result, and some numerical simulations, will shed light on the relation between the most preferred tax rate and intermediate rates of turnover.

Result 4 Let $\delta$ denote the tax level corresponding to full insurance and let $D$ denote the relative utility in the two states, i.e., $D \equiv \exp \left(\gamma\left(c_{e}-c_{u}\right)\right)$, at the employed median voter's most preferred value of $\tau$. Then:

- The most preferred tax rate is unique and satisfies $\tau<\delta$.

- If the most preferred tax is strictly positive, it satisfies,

$$
\tau=\delta-\delta \frac{\ln \left(D^{1+r}\right)+\ln (1-q+q D)-\ln ((1-h) D+h)}{\gamma r w}
$$

were $D$ is the unique solution to

$$
\delta(1+r)=\delta \frac{(1-h) D}{(1-h) D+h}+(1-\delta) \frac{q D}{1-q+q D} .
$$

- If $\delta(1+r)>1$ the non-negativity constraint on $\tau$ will bind so the most preferred tax and insurance rates are zero. 
- Both employed and unemployed have singe-peaked preferences over $\tau$.

- If the most preferred tax rate is strictly positive, the unemployed would prefer higher insurance than the employed.

Proof: In appendix A.4

The functions defining the most preferred value of $\tau$ in result 4 are very nonlinear. To illustrate the relation between turnover, deviations from actuarial fairness and most preferred tax rates, we will use some numerical examples. In the left panel of Figure 2 , we plot the most preferred replacement ratio for employed workers against the rate of turnover, as measured by the unemployment duration $\left(\frac{1}{h}\right)$, for different values of the deviation from actuarial fairness. The other parameters are given in Table 2 and the separation rate $q$ is set to $\frac{h}{10}$ so that the dependency ratio and thus unemployment is kept constant regardless of the rate of turnover. The lower panel shows the same relation but now with the rate of turnover measured by the expected duration of the unemployment period.

Figure 2: Preferred replacement ratio of employed for different deviations from actuarial fairness and turnover rates.

In Figure 2, we see that for all levels of deviations from actuarial fairness, the most preferred tax level increases very steeply in turnover when the latter is low. The highest optimal tax rates are achieved for low rates of turnover, and that these maxima are achieved at lower rates of turnover the higher the deviation from actuarial fairness is. For the four examined values of deviations from actuarial fairness $(0, .03, .10$, and 0.30$)$, the maximum replacement ratio occurs at turnover rates corresponding to an unemployment duration of 18, 80, 143 and 250 months. As turnover increases from these low rates, the most preferred tax level decreases monotonically. ${ }^{10}$

\section{Sequential Voting}

\subsection{Voting over one period}

Let us now consider the case when the median voter chooses the tax rate $\tau \geqslant 0$ and the corresponding unemployment benefits each period. We assume that the median voter decides what tax rate and unemployment benefits will apply next period, i.e., before she knows whether she will become unemployed or not. We also assume that voting takes place each period and that future median voters can not be constrained by any binding arrangements but are free to vote in any way they want.

In addition to assets and employment status, the value functions now clearly depends both on the tax rate determined in the current period and applies in the following period

\footnotetext{
${ }^{10}$ We have not been able to prove that the relation between turnover and most preferred taxes is singlepeaked, nor have we found any combinations of parameters for which this is not the case.
} 
on the tax rates that will apply thereafter. Let $V\left(A_{t}, e, \tau, \tau^{e}\right)$ denote the value function for the employed median voter who at time $t$ expects taxes to be set to $\tau^{e}$ from $t+2$ and himself sets the tax rate to $\tau$ for $t+1 .{ }^{11}$ In the appendix we show that

$$
\begin{aligned}
V\left(A_{t}, e, \tau, \tau^{e}\right) & =-e^{-\gamma \frac{r}{1+r} A_{t}} \frac{1+r}{r} e^{-\gamma c_{e, 1}} \\
V\left(A_{t}, u, \tau, \tau^{e}\right) & =-e^{-\gamma \frac{r}{1+r} A_{t}} \frac{1+r}{r} e^{-\gamma c_{u, 1}}
\end{aligned}
$$

where $c_{e, 1}$ and $c_{u, 1}$ are functions of the parameters of the problem and $\tau$ and $\tau^{e}$. Consumption is given by

$$
c_{t}= \begin{cases}\frac{r}{1+r} A_{t}+c_{e, 1} & \text { if employed } \\ \frac{r}{1+r} A_{t}+c_{u, 1} & \text { if unemployed }\end{cases}
$$

From (14), we see that expected utility is proportional to $e^{-\gamma \frac{r}{1+r} A_{t}}$ so preferences over $\tau$ are independent of wealth. As before, it is then easy to identify the median voter as any of the employed. Furthermore, this implies that there is no strategic motive involved in voting. Changing the tax rate for $t+1$, only affects the asset distribution in the future. Since assets are irrelevant for preferences over tax rates, the current median voter cannot affect future votes if we restrict the attention to Markov strategies. She thus only have to consider what is her preferred tax rate until next vote. This implies that the median voter solves

$$
\max _{\tau} V\left(A_{t}, e, \tau, \tau^{e}\right)
$$

A rational expectations dynamic voting equilibrium must then have the property that if the current employed median voter believes that the decision on the tax rate is going to be $\tau^{e}$ from the next period and onwards she votes for $\tau^{e}$ today. In a dynamic voting equilibrium with one period voting cycles we thus require that

$$
\tau^{e}=\arg \max _{\tau} V\left(A_{t}, e, \tau, \tau^{e}\right)
$$

Now consider the most preferred lon-run tax rate, i.e., the tax rate the currently employed would prefer if it was fixed forever. The question is whether that tax rate, denoted $\tau^{*}$, can be sustained in a sequential voting equilibrium. The following result states that this is not the case.

\footnotetext{
${ }^{11}$ The tax rate in the current period is also set to $\tau^{e}$, although it is straightforward to change that assumption. We could compute the value function for all possible sequences of tax rates, although this may require some tedious calculations. Preferences over tax rates are independent of wealth for all such sequences.
} 
Result 5 Define the most preferred long-run tax rate for the employed as $\tau^{*} \equiv \arg \max _{\tau} V(e, \tau)$. If $\tau^{*}>0$ it cannot be sustained in a voting equilibrium where the median voter sets the tax rate for one period at a time.

Proof: In appendix A.6.

The previous result comes from that the median voter is subject to a strictly positive temptation to reduce next periods insurance, if it thereafter is set the long-run optimum. In other words, there is a tension between the long and short-run interests of the employed. It turns out that this tension may be quite strong. For the ranges of parameter values considered, the median voter prefers the corner solution $\tau=0$ for all expectations about future $\tau$. When this applies, we have a much stronger version of the previous result, namely that the only possible time consistent dynamic voting equilibrium is zero unemployment insurance.

We now want to quantify the temptation to deviate from the long run most preferred insurance and set it to zero during the next period. We are particularly interested in how this temptation varies with the degree of turnover. To study this, we compute the most preferred long-run tax rate $\tau^{*}$ for different values of the turnover, still holding unemployment constant. We then calculate $V\left(A_{t}, e, 0, \tau^{*}\right)=-e^{-\gamma \frac{r}{1+r}} A_{t} \frac{1+r}{r} e^{-\gamma c_{e, 1}}$, i.e., the expected utility when next period's tax and insurance are zero but are set to the long-run optimum thereafter.

Knowing $c_{e, 1}$, it is straightforward to calculate the equivalent variation of a one-period deviation to zero insurance. From (14) and (15), we see that a cash transfer of $\left(c_{e, 1}-\right.$ $\left.c_{e}\right) \frac{1+r}{r}$ yields the same consumption and utility increase as the one period deviation to zero insurance. The former value can thus be interpreted as the equivalent variation, $E V$. We then calculate the cost of the next periods insurance, i.e., its expected discounted price $\left(\frac{w}{1+r}\left((1-q) \tau^{*}-q \tau^{*}(1-a) / d\right)\right)$, denoted $P$.

In Figure 3 we plot $P-E V$ expressed in percent of $P$ against the expected lengths of the unemployment period $(1 / h) .{ }^{12}$ If $P-E V$ equals $P$, the equivalent variation of removing the insurance for one period is zero, i.e., the insurance is worth its price. If $P-E V$ is zero, on the other hand, the employed consider the insurance during the coming period as a pure transfer to the unemployed, i.e., they do not value the insurance component at all. For intermediate values, they assign some value to the insurance component. The temptation to deviate is, of course, larger the lower is $(P-E V) / P$.

Figure 3: Value of next periods insurance relative to its cost

In figure 3 we see that value of next periods insurance relative to its cost decreases as turnover decreases. For the highest degrees of turnover, the value of the insurance is around half its price. For longer durations, the main part of the cost of unemployment

\footnotetext{
${ }^{12}$ The separation rate, $q$ is still adjusted to keeping unemployment constant and $a=0, w=1, r=3 \%$ per year and $\gamma=2$.
} 
insurance is a pure transfer to the unemployed, generating a substantial temptation to deviate.

Conjecture 2 The temptation to deviate from the most preferred long-run insurance level and set it to zero for the next period increases as the turnover decreases. ${ }^{13}$

\subsection{Voting over several periods}

Now let us consider the intermediate case, when taxes can be fixed for some finite number $s>1$ of periods. As above, we assume that the tax rate is set one period before it begins to apply, so the voter does not know her employment status when the tax rate begins to apply. The tax rate that is determined at $t$ thus applies to $t+1 \ldots t+s$. In the appendix we derive the value functions for the case when the tax rate is set to $\tau$ for $s$ periods and thereafter set to $\tau^{e}$, where $\tau$ and $\tau^{e}$ are allowed to take any value $\geqslant 0$. We show in the appendix that the value functions are

$$
\begin{aligned}
V\left(A_{t}, e, \tau, \tau^{e}, s\right) & =-e^{-\gamma \frac{r}{1+r} A_{t}} \frac{1+r}{r} e^{-\gamma c_{e, s}} \\
V\left(A_{t}, u, \tau, \tau^{e}, s\right) & =-e^{-\gamma \frac{r}{1+r} A_{t}} \frac{1+r}{r} e^{-\gamma c_{u, s}}
\end{aligned}
$$

where $c_{e, s}$ and $c_{u, s}$ depend on parameters and $s, \tau$ and $\tau^{e}$. Consumption at the beginning of the $s$ periods is given by

$$
c_{t}= \begin{cases}\frac{r}{1+r} A_{t}+c_{e, s} & \text { if employed } \\ \frac{r}{1+r} A_{t}+c_{u, s} & \text { if unemployed }\end{cases}
$$

To analyze preferences over tax rates $\tau$ for given levels of $s$ and $\tau^{e}$, we can thus disregard wealth as before and voting is non-strategic under Markov strategies. This is an important property of the value functions. If preferences depend on assets, the current median voter can affect future votes since her vote affect future assets distributions. This means that it becomes very cumbersome to calculate the long run consequences of offsteady state votes by the current median voter.

In the previous section, we found that the median voter always prefers an insurance level lower than the most preferred long-run when votes are taken each period. Our numerical results also suggested that the preferred insurance level may be zero in this case. Increasing the length of the voting cycle increases the insurance motive by increasing the risk of being unemployed during the period of time which the unemployment benefit in question is to apply. The following results states this idea more precisely.

Result 6 Let $\tau>0$ denote the tax rate in a dynamic voting equilibrium with one period voting cycles. The current median voter's most preferred tax rate for the next period is

\footnotetext{
${ }^{13}$ We have not been able to prove this analytically nor have we found any numerical counterexamples. It remains to be established, however, whether the conjecture is generally true.
} 
then by assumption $\tau$. If $1-h>q$, the current median voter would like the tax rate two periods ahead to be strictly larger than $\tau$.

Proof: In appendix A.7

The assumption $1-h>q$ implies that the probability of being employed at some future date is always higher for a currently employed person than for an unemployed person. Given this assumption, it is straightforward to extend the proposition in the previous result to periods further in the future.

Given result 6 , we expect the median voter to become more favorable to high taxes and unemployment insurance during the next voting cycle as voting cycles become longer. Making the voting cycle longer may thus be a way of making high unemployment insurance feasible in a voting equilibrium. Another way of doing this is to increase the implementation lag. As the implementation lag becomes longer, the impact of the current employment status on insurance preferences approaches zero. The most preferred level of insurance of both unemployed and employed then converges to the one chosen "behind the veil of ignorance", which, in the case of actuarial fairness, is full insurance.

How the length of the voting cycle affects insurance preferences may depend on the turnover rate, since the difference between long-run and short-run interests of the employed depends on turnover. To analyze this dependence, consider the following experiment. Set $\tau^{e}$ to the value preferred by an employed agent in the low and high turnover economies, if it was to be fixed forever. As we saw in previous sections, this tax rate corresponded to replacement ratios of $69 \%$ and $66 \%$ when the insurance is actuarially fair. Let us now consider whether an employed person would prefer taxes to be set to zero during the coming $s$ periods (months) rather than being kept at $\tau^{e}$ for all periods. This will clearly depend on $s$, and we expect that for large enough $s, \tau^{e}$ may be preferred to zero. In the previous section, we found that if $s$ is 1 , zero taxes are preferred while if $s$ was infinity, $\tau^{e}$ (as well as all other lower taxes) would be strictly preferred to zero.

Figure 4: Consumption increase of employed persons if insurance is zero for the next voting cycle

In Figure 4 we plot the temptation to deviate from the most preferred long-run insurance, represented by the increase in consumption generated $\left(c_{e, s}-c_{e}\right)$ at the time of the deviation against $s$, expressed in years for the two cases. Two things should be noted here:

- First, in both turnover cases the median voters prefer zero insurance during the coming voting period even if the voting cycle is rather long. We actually need voting cycles exceeding 20 years for the median voter to prefer the most preferred long-run insurance over zero.

- Second, the value the employed attach to a deviation to zero insurance for one voting period for shorter voting cycles, is substantially higher when turnover is low. 
When the voting cycle is around 5 years, the value of deviating from the long-run high insurance optimum, measured by the increase in consumption, is several times higher in the low turnover case. The temptation to deviate from a high insurance is thus particularly strong when turnover is low.

We may now look for a time consistent dynamic voting equilibrium. Here this means that if the median voter, who is employed, expects a tax rate of $\tau^{*}$ from the next voting period and onwards, she votes for the same tax rate now and thus sets $\tau=\tau^{*}$ for the coming $s$ periods. We thus require that a time consistent dynamic voting equilibrium for the tax rate $\tau^{*}$ satisfies

$$
\tau^{*}=\arg \max _{\tau} V\left(A_{t}, e, \tau, \tau^{*}, s\right)
$$

The previous results indicate that the voting cycle must be rather long to generate non-trivial tax rates and unemployment benefits. Using numerical methods, it is straightforward to find the solutions to (20) for different lengths of the voting cycle. Voting equilibria for different lengths of the voting cycle are plotted in Figure 5. The unemployment duration is, as above, 18 months in the low turnover case and 6 months in the high turnover case. The deviation from actuarial fairness is zero in both cases. Two things should be noted in the figure. First, the voting cycle has to be very long to generate voting equilibria with high replacement ratios - even a 15-year voting cycle is not long enough to support particularly high replacement ratios. Second, the higher temptation to deviate in the low turnover case depicted in figures 3 and 4, entails a lower supportable replacement ratio in the low turnover case.

Figure 5: Voting equilibrium replacement ratios for different voting cycles

No positive unemployment insurance can be sustained in a dynamic voting equilibrium with Markov strategies when voting cycles are short. ${ }^{14}$ With, voting cycles below 10 years, the median voter always prefers zero insurance for the coming voting period. With higher future insurance, the expected utility of an employed increases, particularly in the low turnover case, but she still prefers zero insurance for the coming four years.

As in the previous section, we can evaluate the temptation to deviate to zero insurance for the coming voting cycle from the most preferred long-run $\tau^{e}$ by studying the consumption increase generated by such a deviation. In Figure 6 we depict this for different lengths of the voting cycle. We see that the temptation to deviate increases as turnover decreases. We also see that the temptation to deviate increases with the length of the voting cycle when turnover is sufficiently low. We make the following interpretation of this finding. As turnover decreases for a given length of the voting cycle, the value of

\footnotetext{
${ }^{14}$ If the Markov assumption is relaxed, this may, of course, no longer be the case.
} 
the insurance during the next voting cycle decreases and the temptation to deviate thus increases. The temptation to deviate can, however, never be higher than the cash value of the insurance premiums payed during the voting cycle. This puts an upper limit for the temptation to deviate. This limit increases proportionally as the voting cycle increases. For sufficiently low rates of turnover, the temptation to deviate is close to this upper limit. On the other hand, when turnover is high relative to the voting cycle, increasing the length of the voting may increase the value of the insurance component. This may produce a non-monotonicity of the temptation to deviate with respect to the voting cycle as illustrated by the crossing curves in Figure 6 .

Figure 6: Temptation to deviate and unemployment duration

\section{Concluding Discussion}

Before making some concluding remarks, let us summarize our main results. First, the degree of flow in and out of unemployment is important for preferences over different levels of unemployment insurance. Low turnover means that the income shock associated with getting unemployed is highly persistent. In this case, self-insurance via a capital market is a bad substitute for unemployment insurance. It is then in the long-run interest of the employed (as well as, of course, of the unemployed) to have an unemployment insurance with high replacement ratios, even when the system is inefficient or actuarially unfair for other reasons.

Second, there is a tension between the long and short-run interest of the employed which prevents the long-run good from being achieved in a sequential voting equilibrium. The median voter prefers an insurance system with low replacement rates today but increasing over time. This is not feasible in a sequential voting equilibrium without a possibility to bind the future voters. The tension between the long and the short-run depends on the turnover rate. If unemployment insurance is introduced, the expected utility of employed individuals increases more the lower is the turnover. However, the lower the turnover, the stronger is the immediate temptation to reduce the insurance and the taxes financing it in the near future.

We have shown that our first result above critically depends on the assumption that people can save and borrow. In our model, we made the rather unrealistic assumption that everybody has access to a perfect capital market. We thus need to consider the potential consequences of borrowing limits and other capital market imperfections. Such assumptions complicate the model substantially. In particular, preferences about the insurance level become dependent on current assets, thus making it more difficult to find the median voter. What is probably more important is that if preferences depend on assets, the current median voter can change the behavior of the future median voter by affecting the wealth distribution via the insurance system. Finding a dynamic voting 
equilibrium is then at best difficult ( Krusell et al. [5] show examples where this is possible, however).

We do, however, believe that such modifications of the model would not change the first result qualitatively. When borrowing limits exist, the persistence in the shocks becomes even more important. With low persistence, borrowing constraints are less likely to be binding and would not affect substantially precautionary savings. On the other hand, with high persistence, a borrowing constraint may have a substantial effect on precautionary savings and expected utility if no insurance exists. Our conjecture is thus that borrowing constraints would tend to enforce the mechanism discussed in this paper by making self-insurance an even worse substitute for unemployment insurance when employment turnover is low. Other capital market imperfections are likely to have similar effects since alternatives to the capital market, like borrowing from friends and family or letting household durables depreciate, are reasonable substitutes for the capital market unless shocks are too persistent.

For analytical tractability, we have relied on the exponential (constant absolute risk aversion) utility function, which, together with the assumptions of constant wages and infinite horizons produces value functions of relatively simple form. The fact that we use this utility function is one reason why we stress that the quantitative results have to be taken at face value. Nevertheless, we think that our results illustrate mechanisms of quantitative importance. Simulations, in, for example, a stochastic growth model should be undertaken to further explore the quantitative implications of the mechanisms we have analyzed.

Our second finding was that the short-run and long-run interest of the employed diverge. This implies that it may be difficult to sustain an insurance system with high replacement ratios when turnover is low even though this is in the long-run interest of the employed (and, of course, the unemployed). The observation that unemployment insurance is generous and turnover is low in Europe was the starting point of this paper. The first finding provides us with a motive - low turnover is likely to make the employed want a high unemployment insurance. The second finding shows that the means may not exist. We do think, however,that our second finding points in an interesting direction. It shows that the employed in Europe have more to gain than the employed in U.S. by building institutions that facilitate long-run arrangements of the unemployment insurance. Similarly, the stronger tension between the short-run interest of employed and unemployed may also make it more important for the employed to try to build institutions where the unemployed have considerable political influence. We think that universal unemployment insurance coverage, unions and political labor parties are all means that can contribute to achieving such long-run social contracts. Such institutions may thus be more likely to develop in low turnover economies.

We have in this paper not explicitly modelled individual heterogeneity with respect to separation and hiring rates. We have showed that preferences are single peaked, so a 
majority voting mechanism would result in the median voters preferences determining the insurance rate. Our finding that preferences are non-monotonic in turnover implies that it may not be immediate to identify the median voter. Employed individuals with very low turnover and individuals with high turnover may share a low interest in unemployment insurance. The non-monotonicity also means that changes in the distribution of turnover rates may have substantial effects on politically chosen unemployment insurance rates also if they leave the mean and median turnover rates unchanged. For example, say that there is primary sector with very low turnover, for instance a public sector with lifelong employment. In addition, assume there is a secondary sector with very high turnover, for example a non-regulated private sector. Now assume that the lifelong employment contracts in the primary sector are terminated and that job-protection legislation is introduced in the secondary sector. This would then increase turnover in the primary sector and decrease it in the secondary. Both these factors would lead to an increase in the number of individuals who prefer high unemployment insurance and the median voter is likely to change leading to a political choice of higher unemployment insurance. Allowing ourselves to be speculative, we think that this sketches a development that may have occurred in many European countries during, say, the last two or three decades.

Another issue that we have not dealt with explicitly is why turnover is lower in Europe. There may be several explanations to this, of which labor market regulations and lower tendency to move are two. Another explanation is developed in Marimon \& Zilibotti [6]. They assume that the degree of specialization differs between Europe and the U.S. The educational system in the U.S. seems to provide less specialized skills than, for example, the German vocational high school programs. It may also be reasonable to assume that learning-by-doing is a kind of training that results in a relatively high degree of specialization. The longer average duration of a job in Europe may then lead to more specialized individuals. A more specialized individual has more to gain from by being "picky" when looking for a job. she may expect a higher wage and a longer lasting job, but at the price of a longer search time.

It follows from the discussion in the previous paragraph that if the the turnover rate is endogenized, we may have a feed-back mechanism from the choice of unemployment insurance to the rate of turnover. The cost of a long expected searching time is lower when unemployment insurance is high. Furthermore, the relatively risky strategy of choosing a high degree of human capital specialization is more attractive if the unemployment insurance is generous. We explore a model with such a feed-back mechanism in appendix A.8. We extend the model in section 2.2 by assuming that labor market entrants can make a permanent choice of turnover. We show that this can produce multiple stationary states. Given that employed individuals previously chose high (low) turnover, they now prefer low (high) unemployment insurance. This, in turn, affects entrants to the labor market so that they choose high (low) turnover.

A last issue we want to mention concerns limits on the unemployment benefits. We 
have shown that the employed individuals have a strong motive to insure against long spells of unemployment. Short spells can more easily be handled through self-insurance. This implies that unemployment insurance that covers only a limited (short) period of unemployment appears misguided from a purely insurance based point of view. This may be an explanation for the strong opposition in many European countries against imposing a time limit on unemployment benefits. This statement, as most of the analysis in this paper, is positive. Normative conclusions about the level of insurance must certainly take into account many factors that has been outside the scope of this paper. An important example of such factors is the moral hazard problem due to imperfect control of the individual's search intensity. The low rates of turnover found in Europe may cause a severe conflict between the goals of providing good insurance against bad luck on the labor market and constructing an unemployment insurance that mitigates various moral hazard problems.

\section{A Appendix}

\section{A.1 Consumption and Value Functions with Infinite Voting Cycle}

To derive the infinite horizon solution we start with the finite horizon problem and let the horizon go to infinity. At $T-1$, the value function for an employed individual is given by

$$
\begin{aligned}
V\left(A_{T-1}, e\right)= & \max _{c_{T-1}}\left\{-e^{-\gamma c_{T-1}}\right. \\
& -\frac{1}{1+r}\left[(1-q) e^{-\gamma\left((1+r)\left(A_{T-1}+w_{e}-c_{T-1}\right)+w_{e}\right)}\right. \\
& \left.\left.+q e^{-\gamma\left((1+r)\left(A_{T-1}+w_{e}-c_{T-1}\right)+w_{u}\right)}\right]\right\}
\end{aligned}
$$

with first order condition

$$
\begin{aligned}
e^{-\gamma c_{T-1}}= & (1-q) e^{-\gamma\left((1+r)\left(A_{T-1}+w_{e}-c_{T-1}\right)+w_{e}\right)} \\
& +q e^{-\gamma\left((1+r)\left(A_{T-1}+w_{e}-c_{T-1}\right)+w_{u}\right)}
\end{aligned}
$$

Now define, $R_{s} \equiv(1+r)^{s}\left(\sum_{t=0}^{s}(1+r)^{t}\right)^{-1}$. This is the annuity factor; $R_{s} A_{t}$ is the maximum constant consumption level that can be supported with financial assets $A_{t}$ and $s$ periods left until the last period. The solution to the first order condition (22) can be written as $R_{1} A_{T-1}+c_{e, T-1}$. Substituting this into the first order condition and simplifying yields

$$
\begin{aligned}
e^{-\gamma\left(R_{1} A_{T-1}+c_{e, T-1}\right)=} & (1-q) e^{-\gamma\left(R_{1} A_{T-1}+(1+r)\left(w_{e}-c_{e, T-1}\right)+w_{e}\right)} \\
& +q e^{-\gamma\left(R_{1} A_{T-1}+(1+r)\left(w_{e}-c_{e}, T-1\right)+w_{u}\right)} \\
e^{-\gamma c_{e}, T-1}= & (1-q) e^{-\gamma\left((1+r)\left(w_{e}-c_{e}, T-1\right)+w_{e}\right)} \\
& +q e^{-\gamma\left((1+r)\left(w_{e}-c_{e, T-1}\right)+w_{u}\right)}
\end{aligned}
$$

Using this in the value function yields

$$
\begin{aligned}
V\left(A_{T-1}, e\right) & =-e^{-\gamma\left(R_{1} A_{T-1}+c_{e, T-1}\right)}-\frac{1}{1+r} e^{-\gamma\left(R_{1} A_{T-1}+c_{e, T-1}\right)} \\
& =-R_{1}^{-1} e^{-\gamma\left(R_{1} A_{T-1}+c_{e, T-1}\right)}
\end{aligned}
$$


Repeating this for the problem of an unemployed agent at $T-1$ yields

$$
V\left(A_{T-1}, u\right)=-R_{1}^{-1} e^{-\gamma\left(R_{1} A_{T-1}+c_{u, T-1}\right)} .
$$

Iterating backwards and using $c_{T-s}=R_{s} A_{T-s}+c_{e, T-s}$ for the employed and $c_{T-s}=R_{s} A_{T-s}+$ $c_{u, T-s}$ for the unemployed, it is easy to verify that

$$
\begin{aligned}
V\left(A_{T-s}, e\right) & =-R_{s}^{-1} e^{-\gamma\left(R_{s} A_{T-s}+c_{e, T-s}\right)} \\
V\left(A_{T-s}, u\right) & =-R_{s}^{-1} e^{-\gamma\left(R_{s} A_{T-s}+c_{u, T-s}\right)}
\end{aligned}
$$

The limiting value functions when $s \rightarrow \infty$ are

$$
\begin{aligned}
V\left(A_{t}, e\right) & =-\frac{1+r}{r} e^{-\gamma\left(\frac{r}{1+r} A_{t}+c_{e}\right)} \equiv e^{-\gamma \frac{r}{1+r} A_{t}} V(e) \\
V\left(A_{t}, u\right) & =-\frac{1+r}{r} e^{-\gamma\left(\frac{r}{1+r} A_{t}+c_{u}\right)} \equiv e^{-\gamma \frac{r}{1+r} A_{t}} V(u)
\end{aligned}
$$

with $c_{e}$ and $c_{u}$ satisfying

$$
\begin{gathered}
e^{-\gamma c_{e}}=(1-q) e^{-\gamma\left(r\left(w_{e}-c_{e}\right)+c_{e}\right)}+q e^{-\gamma\left(r\left(w_{e}-c_{e}\right)+c_{u}\right)} \\
e^{-\gamma c_{u}}=(1-h) e^{-\gamma\left(r\left(w_{u}-c_{u}\right)+c_{u}\right)}+h e^{-\gamma\left(r\left(w_{u}-c_{u}\right)+c_{e}\right)}
\end{gathered}
$$

which, as shown in the next section, always has a unique solution for $c_{e}$ and $c_{u}$. Consumption is given by (11).

\section{A.2 Existence and Uniqueness of the Value Function}

Let us now show that there is always a unique solution to (27). Define $x \equiv \exp \left\{-\gamma c_{e}\right\}, y \equiv$ $\exp \left\{-\gamma c_{u}\right\}, D \equiv \frac{y}{x}=\exp \left\{\gamma\left(c_{e}-c_{u}\right)\right\}, W \equiv \exp \left\{\gamma r w_{e}\right\}$ and $B \equiv \exp \left\{\gamma r w_{u}\right\} . D$ is the ratio of the utility of an unemployed person to the utility of an employed person if they have the same assets. We can then rewrite (27) as

$$
\begin{aligned}
W x^{r} & =(1-q)+q D \\
B y^{r} & =(1-h)+h D^{-1}
\end{aligned}
$$

Giving

$$
\frac{W}{B}=D^{r} \frac{(1-q)+q D}{(1-h)+h D^{-1}}
$$

Note that (28) and (29) only have one unknown variable, $D$. If we find a solution for this equation, we have also found $x$ and $y$ (given (28)), and consequently $c_{e}$ and $c_{u}$, as well as $V(L)$ and $V(U)$. Now, let the function $A(D)$ be defined by the RHS of (29). It is easy to see that $\frac{\partial A(D)}{\partial D}>0$ and

$$
\begin{aligned}
A(1) & =1 \\
\lim _{D \rightarrow 0} A(D) & =0 \\
\lim _{D \rightarrow \infty} A(D) & =\infty
\end{aligned}
$$

Given that the left hand side of (29) is constant, and the right hand side monotonically increasing and with a range from 0 to $\infty$, there must be a unique solution to (29). Moreover, the 
solution to (29) requires that

$$
\begin{aligned}
& \frac{W}{B}>1 \Leftrightarrow D^{*}>1 \\
& \frac{W}{B}=1 \Leftrightarrow D^{*}=1 \\
& \frac{W}{B}<1 \Leftrightarrow D^{*}<1
\end{aligned}
$$

If the employed are politically decisive, the utility will be higher for the employed than for the unemployed. This implies that net wages are higher than unemployment benefits so $\frac{W}{B}>1$. Given this, it is easy to observe that $w_{e}>c_{e}>c_{u}>w_{u}$. This follows from, $D>1$ and (28)

$$
\begin{aligned}
w_{e}-c_{e} & =\frac{\log ((1-q)+q D)}{\gamma r}>0 \\
w_{u}-c_{u} & =\frac{\log \left(1-h+h D^{-1}\right)}{\gamma r}<0 .
\end{aligned}
$$

\section{A.3 Optimal taxes with infinite turnover}

Consider the continuous time version of the model where $h$ represents the instantaneous hiring rate, which is allowed to take any positive value. Take a currently unemployed person. Denote the time until she finds a job by $\tau$ which is a stochastic variable with a density function $f(\tau)=h e^{-h \tau}$. Let us consider an unemployed individual who follows the (weakly) suboptimal plan of consuming $w_{u}+r A_{t}$ during her current unemployment period. When she finds her next job she reverts to the optimal behavior. Denote the conditional value function of this individual $W\left(A_{t}, u, \tau\right)$ where $\tau$ denotes her expected utility if she finds a job exactly $\tau$ units from now. We then have

$$
\begin{aligned}
W\left(A_{t}, u, t\right) & =-\int_{0}^{\tau} e^{-r s} e^{-\gamma\left(r A_{t}+w_{u}\right)} d s+e^{-r \tau} V\left(A_{t}, e\right) \\
& =e^{-\gamma\left(r A_{t}+w_{u}\right)} \frac{1-e^{-r \tau}}{r}+e^{-r \tau} V\left(A_{t}, e\right)
\end{aligned}
$$

Clearly the unconditional value function, denoted $W\left(A_{t}, u\right)$ satisfies

$$
V\left(A_{t}, u\right) \geq W\left(A_{t}, u\right) \equiv \int_{0}^{\infty} W\left(A_{t}, u, \tau\right) f(\tau) d \tau
$$

So:

$$
\begin{array}{ccc}
W\left(A_{t}, u\right) & \\
= & -\int_{0}^{\infty}\left(e^{-\gamma\left(r A_{t}+w_{u}\right)} \frac{1-e^{-r \tau}}{r}+e^{-r \tau} V\left(A_{t}, e\right)\right) h e^{-h \tau} d \tau \\
= & \frac{-e^{-\gamma\left(r A_{t}+w_{u}\right)}}{r} \int_{0}^{\infty}\left(1-e^{-r \tau}\right) h e^{-h \tau} d \tau+V\left(A_{t}, e\right) \int_{0}^{\infty} e^{-r \tau} h e^{-h \tau} d \tau \\
= & \frac{-e^{-\gamma\left(r A_{t}+w_{u}\right)}}{r}\left(1-\frac{h}{r+h}\right)+V\left(A_{t}, e\right) \frac{h}{r+h}
\end{array}
$$

Now take the limit of both sides as $h \rightarrow \infty$. We then see that

$$
\lim _{h \rightarrow \infty} W\left(A_{t}, u\right)=\lim _{h \rightarrow \infty} V\left(A_{t}, e\right)
$$

Now we have that $V\left(A_{t}, e\right) \geq V\left(A_{t}, u\right) \geq W\left(A_{t}, u\right)$ since $W$ denotes a sub-optimal plan and the wage is assumed to be higher when a person employed than when unemployed. So 


$$
\lim _{h \rightarrow \infty} V\left(A_{t}, u\right)=V\left(A_{t}, e\right)
$$

\section{A.4 Utility maximizing insurance}

Maximizing the utility of the employed workers over $\tau$ is equivalent to maximizing $c_{e}$. From (32), we have

$$
c_{e}=(1-\tau) w-\frac{\ln (1-q+q D)}{\gamma r} .
$$

Now note that $w_{e}-w_{u}=w(1-\tau)-w \tau \frac{1-a}{d}=w\left(1-\frac{\tau}{\delta}\right)$, where $\delta$ is the tax rate corresponding to full insurance. Using this in (29) and taking logs, we obtain

$$
\tau=\delta-\delta \frac{\ln \left(D^{1+r}\right)+\ln (1-q+q D)-\ln ((1-h) D+h)}{\gamma r w} .
$$

This establishes a monotonic negative relation between $\tau$ and $D$. Certainly, the employed will never want $\tau$ to be higher than $\delta$ (full insurance), and non-negativity of $\tau$ implies that $D$ can not be higher than some value $\bar{D}>1$, which is the unique value satisfying

$$
\ln \left(\bar{D}^{1+r}\right)+\ln (1-q+q \bar{D})-\ln ((1-h) \bar{D}+h)=\gamma r w .
$$

Substituting $\tau$ from (39) in (38) we can express the utility of employed agents as a function of, $D$, the relative utility in the two states.

$$
c_{e}=w(1-\delta)+\frac{\left[\delta \ln \left(D^{1+r}\right)-[\delta \ln ((1-h) D+h)+(1-\delta) \ln (1-q+q D)]\right]}{\gamma r}
$$

Consequently, the problem is reduced to maximizing equation (41) for values of $D$ belonging to the interval $[1, \bar{D}]$. The first and second derivatives of $(38)$ are

$$
\frac{\partial c_{e}}{\partial D}=\frac{1}{\gamma r D}\left[\delta(1+r)-\left\{\delta \frac{(1-h) D}{(1-h) D+h}+(1-\delta) \frac{q D}{1-q+q D}\right\}\right]
$$

and

$$
\frac{\partial^{2} c_{e}}{\partial D^{2}}=-\frac{\frac{\partial c_{e}}{\partial D}}{D}-\frac{1}{\gamma r D}\left[\delta \frac{(1-h) h}{[(1-h) D+h]^{2}}+(1-\delta) \frac{(1-q) q}{[1-q+q D]^{2}}\right]
$$

which is negative whenever (42) is zero.

Now let

$$
J(D)=\delta \frac{(1-h) D}{(1-h) D+h}+(1-\delta) \frac{q D}{1-q+q D}
$$

The first order condition for the most preferred $\tau$ can then be written as $J(D)=\delta(1+r)$. It is clear that $J($.$) is increasing monotonically with J(0)=0$ and $\lim _{D \rightarrow \infty} J(D)=1$.

Consequently:

- If $\delta(1+r)>1$, there is no interior maximum for $c_{e}$, since its first derivative is always positive. The non-negativity of taxes implies that the tax level that employed agents prefer is zero (and $D=\bar{D}$ ). 
- If $\delta(1+r)<1$ and the turnover is zero (i.e., the probabilities $q$ and $h$ are both zero), then $J(D)=\delta<\delta(1+r)$ for all values of $D$. The tax level preferred by employed agents is zero also in this case (and $D=\bar{D}$ ).

- If $\delta(1+r)<1$ and the turnover is positive (that is the probabilities $q$ and $h$ are both strictly positive) there is always a unique value of $D$ making the first derivative of $c_{e}$ equal to zero, and at this value, the second derivative is negative. Let us call this value $\tilde{D}$. Note that $\tilde{D}>1$, because $J(1)=\delta(1-h)+(1-\delta) q<\delta(1+r)$.

- If $\bar{D}<\tilde{D}$ (i.e., $\delta(1+r)>J(\bar{D})$ ), then $c_{e}$ increases over the whole interval $[1, \bar{D}]$, consequently the employed agents maximize their utility when $D=\bar{D}$ and $\tau=0$.

- If $\bar{D}>\tilde{D}$ (that is: $\delta(1+r)>J(\bar{D})$ ), then $c_{e}$ achieves its global maximum at the feasible point $\tilde{D}$, and the tax level maximizing the utility of the employed agents is:

$$
\tau=\delta-\delta \frac{\ln \left(\tilde{D}^{1+r}\right)+\ln (1-q+q \tilde{D})-\ln ((1-h) \tilde{D}+h)}{\gamma r w}<\delta
$$

- Employed individuals' preferences over $D$ are single-peaked. Also preferences over tau are single-peaked, since the relation between $D$ and $\tau$ is monotonic.

By solving $J(D)=\delta(1+r)$, we can obtain a closed form value for $\tilde{D}$ :

$$
\tilde{D}=\frac{1}{2}\left(\sqrt{b^{2}-4 c}-b\right)
$$

where (denoting $Q=\frac{1-q}{q}$ and $H=\frac{h}{1-h}$ )

$$
b=\frac{\delta-\delta(1+r)}{1-\delta(1+r)} Q+\frac{1-\delta-\delta(1+r)}{1-\delta(1+r)} H
$$

and

$$
c=-\frac{\delta(1+r)}{1-\delta(1+r)} H Q
$$

Turning to the unemployed, we have $w_{u}=w \tau\left(\frac{1}{\delta}-1\right)$. Using this in (32) and (39) gives,

$$
c_{u}=w(1-\delta)-\frac{1-\delta}{\gamma r}((1+r) \ln D+\ln (1-q+q D)-\ln ((1-h) D+h))-\frac{\ln (1-h+h / D)}{\gamma r}
$$

with

$$
\frac{\partial c_{u}}{\partial D}=-\frac{1}{\gamma r D}\left((1-\delta)\left(1+r+\frac{q D}{1-q+q D}-\frac{(1-h) D}{(1-h) D+h}\right)-\frac{h}{(1-h) D+h}\right) .
$$

and

$$
\frac{\partial^{2} c_{u}}{\partial D^{2}}=\frac{\frac{\partial c_{u}}{\partial D}}{D}-\frac{1}{\gamma r D}\left[\delta \frac{(1-h) h}{[(1-h) D+h]^{2}}+(1-\delta) \frac{(1-q) q}{[1-q+q D]^{2}}\right]
$$

which is negative whenever (50) is zero. This established single-peakedness. 
Using (42) and (50) and simplifying we find that

$$
\frac{\partial c_{e}}{\partial D}-\frac{\partial c_{u}}{\partial D}=\frac{1}{\gamma D}
$$

This shows that at an interior optimum for the employed, the unemployed strictly prefers a lower $D$, i.e., higher insurance.

\section{A.5 Consumption and Value Functions With Finite Voting Cycles}

Assume that the tax rate can be fixed for $s$ periods. The tax rate determined at $t$ applies to $t+1 \ldots t+s$. We derive the value functions when the tax rate is set to $\tau$ for $s$ periods and thereafter set to $\tau^{e}$ for $\tau, \tau^{e} \geq 0$. The tax rate in the current period is also set to $\tau^{e}$, although it is trivial to change that assumption. We derive the value functions $V\left(A_{t}, l, \tau, \tau^{e}, s\right)$ recursively for $s=\{1,2, \ldots\}$.

Now redefine $w_{e} \equiv w\left(1-\tau^{e}\right)$ and $w_{u} \equiv w \tau^{e}(1-a) / d$. With this notation, $w\left(\tau^{e}-\tau\right)$ can be seen as an extra cash transfer to the employed the next period. For the unemployed, the corresponding extra transfer is $w \frac{\left(\tau-\tau^{e}\right)(1-a)}{d}$. When $s=1$, the value functions are given by

$$
\begin{aligned}
V\left(A_{t}, e, \tau, \tau^{e}, 1\right)= & \max _{c_{t}}\left\{-e^{-\gamma c_{t}}\right. \\
& -\frac{1}{1+r}\left[(1-q) V\left(A_{t+1}+w\left(\tau^{e}-\tau\right), e\right)\right. \\
& \left.\left.+q V\left(A_{t+1}+w \frac{\left(\tau-\tau^{e}\right)(1-a)}{d}, u\right)\right]\right\} \\
& \text { s.t. } A_{t+1}=(1+r)\left(A_{t}+w_{e}-c_{t}\right) \\
V\left(A_{t}, u, \tau, \tau^{e}, 1\right)= & \max _{c_{t}}\left\{-e^{-\gamma c_{t}}\right. \\
& -\frac{1}{1+r}\left[(1-h) V\left(A_{t+1}+w \frac{\left(\tau-\tau^{e}\right)(1-a)}{d}, u\right)\right. \\
& +h V\left(A_{t+1}+w\left(\tau^{e}-\tau\right), u\right)[\} \\
& \text { s.t. } A_{t+1}=(1+r)\left(A_{t}+w_{u}-c_{t}\right)
\end{aligned}
$$

where $V(\cdot, \cdot)$ are the previously derived infinite voting cycle value functions. Now let us guess that

the following solution to the consumption problem at time $t$, given $\tau, \tau^{e}$ and $s$ has the following form

$$
c_{t}= \begin{cases}\frac{r}{1+r} A_{t}+\widetilde{c}_{e, s} & \text { if employed } \\ \frac{r}{1+r} A_{t}+\widetilde{c}_{u, s} & \text { if unemployed }\end{cases}
$$

Simplifying, using the explicit form of $V(\cdot, \cdot)$ and using the budget constraint we get

$$
\begin{aligned}
V\left(A_{t}, e, \tau, \tau^{e}, 1\right)= & e^{-\gamma \frac{r}{1+r} A_{t}} \max _{\widetilde{c}_{e, 1}\left\{-e^{-\gamma \widetilde{c}_{e, 1}}\right.} \\
& -\frac{1}{r}\left[(1-q) e^{-\gamma\left(\frac{r}{1+r} w\left(\tau^{e}-\tau\right)+r\left(w_{e}-\widetilde{c}_{e, 1}\right)+c_{e}\right)}\right. \\
& +q e^{-\gamma\left(\frac{r}{1+r} \frac{w\left(\tau-\tau^{e}\right)(1-a)}{d}+r\left(w_{e}-\widetilde{c}_{e, 1}\right)+c_{u}\right)}[\} \\
V\left(A_{t}, u, \tau, \tau^{e}, 1\right)= & e^{-\gamma \frac{r}{1+r} A_{t}} \max _{\widetilde{c}_{e, 1}}\left\{-e^{-\gamma \widetilde{c}_{u, 1}}\right. \\
& -\frac{1}{r}\left[(1-h) e^{-\gamma\left(\frac{r}{1+r} w\left(\tau-\tau^{e}\right)(1-a)\right.}+r\left(w_{u}-\widetilde{c}_{u, 1}\right)+c_{u}\right) \\
& +h e^{-\gamma\left(\frac{r}{1+r} w\left(\tau^{e}-\tau\right)+r\left(w_{u}-\widetilde{c}_{u, 1}\right)+c_{e}\right)}[\}
\end{aligned}
$$

Let the choice variables without tildes denote their optimized values. The first order conditions are then 


$$
\begin{aligned}
e^{-\gamma c_{e, 1}}= & (1-q) e^{-\gamma\left(\frac{r}{1+r} w\left(\tau^{e}-\tau\right)+r\left(w_{e}-c_{e, 1}\right)+c_{e}\right)} \\
& +q e^{-\gamma\left(\frac{r}{1+r} \frac{w\left(\tau-\tau^{e}\right)(1-a)}{d}+r\left(w_{e}-c_{e, 1}\right)+c_{u}\right)} \\
e^{-\gamma c_{u, 1}}= & (1-h) e^{-\gamma\left(\frac{r}{1+r} \frac{w\left(\tau-\tau^{e}\right)(1-a)}{d}+r\left(w_{u}-c_{u, 1}\right)+c_{u}\right)} \\
& +h e^{-\gamma\left(\frac{r}{1+r} w\left(\tau^{e}-\tau\right)+r\left(w_{u}-c_{u, 1}\right)+c_{e}\right)}
\end{aligned}
$$

which are satisfied for all $A_{t}$ for the proper choice of $c_{e, 1}$ and $c_{u, 1}$ thus confirming (55). Using the first order conditions, the value functions are

$$
\begin{aligned}
V\left(A_{t}, e, \tau, \tau^{e}, 1\right) & =-e^{-\gamma \frac{r}{1+r} A_{t}} \frac{1+r}{r} e^{-\gamma c_{e, 1}} \\
V\left(A_{t}, u, \tau, \tau^{e}, 1\right) & =-e^{-\gamma \frac{r}{1+r} A_{t}} \frac{1+r}{r} e^{-\gamma c_{u, 1}}
\end{aligned}
$$

Now continuing recursively we find that for $s>1$ periods, the value functions are

$$
\begin{aligned}
V\left(A_{t}, e, \tau, \tau^{e}, s\right)= & e^{-\gamma \frac{r}{1+r} A_{t}} \max _{\widetilde{c}_{e, s}+1}\left\{-e^{-\gamma \widetilde{c}_{e, s}}\right. \\
& -\frac{1}{r}\left[(1-q) e^{-\gamma\left(\frac{r}{1+r}\left(A_{t}+w\left(\tau^{e}-\tau\right)\right)+r\left(w_{e}-\widetilde{c}_{e, s+1}\right)+c_{e, s-1}\right)}\right. \\
& +q e^{-\gamma\left(\frac{r}{1+r} \frac{w\left(\tau-\tau^{e}\right)(1-a)}{d}+r\left(w_{e}-\widetilde{c}_{e, s+1}\right)+c_{u, s-1}\right)}[\} \\
V\left(A_{t}, u, \tau, \tau^{e}, s\right)= & e^{-\gamma \frac{r}{1+r} A_{t}} \max _{\widetilde{c}_{u, s+1}}\left\{-e^{-\gamma \widetilde{c}_{u, s}}\right. \\
& -\frac{1}{r}\left[(1-h) e^{-\gamma\left(\frac{r}{1+r} \frac{w\left(\tau-\tau^{e}\right)(1-a)}{d}+r\left(w_{u}-\widetilde{c}_{u, s}\right)+c_{u, s-1}\right)}\right. \\
& \left.\left.+h e^{-\gamma\left(\frac{r}{1+r} w\left(\tau^{e}-\tau\right)+r\left(w_{u}-\widetilde{c}_{u, s}\right)+c_{e, s-1}\right)}\right]\right\}
\end{aligned}
$$

with value functions

$$
\begin{aligned}
V\left(A_{t}, e, \tau, \tau^{e}, s\right) & =-e^{-\gamma \frac{r}{1+r} A_{t}} \frac{1+r}{r} e^{-\gamma c_{e, s}} \\
V\left(A_{t}, u, \tau, \tau^{e}, s\right) & =-e^{-\gamma \frac{r}{1+r} A_{t}} \frac{1+r}{r} e^{-\gamma c_{u, s}}
\end{aligned}
$$

We see that the value functions in (59) are linear in the term $e^{-\gamma \frac{r}{1+r} A_{t}}$. Preferences over tax rates for the coming $s$ periods are thus independent of wealth, just as in the case of constant tax rates. This is clearly true for any sequence of tax rates.

\section{A.6 Temptation to Deviate with One Period Voting Cycles}

Let $V\left(A_{t}, . ., \tau_{1}, \tau_{2}\right)$ denote the value function if tax in the next period is set to $\tau_{1}$ and thereafter to $\tau_{2}$ forever. Now define $\tau^{*}$ as the tax rate that maximizes $V\left(A_{t}, e, \tau\right)$. We then have that

$$
\frac{\partial V\left(A_{t}, e, \tau^{*}, \tau^{*}\right)}{\partial \tau_{1}}=\frac{1}{1+r}\left(( 1 - q ) ( - w ) U ^ { \prime } \left(c\left(A_{t+1}, e\right)+q w \frac{1-a}{d} U^{\prime}\left(c\left(A_{t+1}, u\right)\right) .\right.\right.
$$

Now we want to show that (60) is strictly negative, so the temptation to deviate is strictly positive. First assume that the most preferred tax rate is positive so that we have an interior optimum. Since $\tau^{*}$ maximizes $V\left(A_{t}, e, \tau\right)$, it satisfies

$$
\begin{aligned}
0= & \frac{\partial V\left(A_{t}, e, \tau^{*}\right)}{\partial \tau} \\
= & \frac{1}{1+r}\left[( 1 - q ) \left((-w) U^{\prime}\left(c\left(A_{t+1}, e\right)+\frac{\partial V\left(A_{t+1}, e, \tau^{*}\right)}{\partial \tau}\right)\right.\right. \\
& +q\left(w \frac{1-a}{d} U^{\prime}\left(c\left(A_{t+1}, u\right)+\frac{\partial V\left(A_{t+1}, u, \tau^{*}\right)}{\partial \tau}\right)\right] .
\end{aligned}
$$

Now, use that also $\frac{\partial V\left(A_{t+1}, e, \tau^{*}\right)}{\partial \tau}=0$. From this follows that 


$$
\frac{\partial V\left(A_{t}, e, \tau^{*}, \tau^{*}\right)}{\partial \tau_{1}}=0-q \frac{\partial V\left(A_{t+1}, u, \tau^{*}\right)}{\partial \tau}
$$

where the partial derivative is with respect to the first $\tau$, i.e., the tax rate next period. What then remains is to show that $\frac{\partial V\left(A_{t+1}, u, \tau^{*}\right)}{\partial \tau}$ is strictly positive. For this purpose we first note that it follows from (61) that

$$
U^{\prime}\left(c\left(A_{t+1}, e\right)=\frac{q}{(1-q) w}\left(w \frac{1-a}{d} U^{\prime}\left(c\left(A_{t+1}, u\right)+\frac{\partial V\left(A_{t+1}, u, \tau^{*}\right)}{\partial \tau}\right) .\right.\right.
$$

For an unemployed person we have

$$
\begin{aligned}
\frac{\partial V\left(A_{t}, u, \tau^{*}\right)}{\partial \tau}= & \frac{1}{1+r}\left[h \left((-w) U^{\prime}\left(c\left(A_{t+1}, e\right)+\frac{\partial V\left(A_{t+1}, e, \tau\right)}{\partial \tau}\right)\right.\right. \\
& +(1-h)\left(w \frac{1-a}{d} U^{\prime}\left(c\left(A_{t+1}, u\right)+\frac{\partial V\left(A_{t+1}, u, \tau\right)}{\partial \tau}\right)\right] .
\end{aligned}
$$

Using (63), we get

$$
\begin{aligned}
& \frac{\partial V\left(A_{t}, u, \tau^{*}\right)}{\partial \tau} \\
= & \frac{1}{1+r}\left[h \left(\frac{q}{q-1}\left(w \frac{1-a}{d} U^{\prime}\left(c\left(A_{t+1}, u\right)+\frac{\partial V\left(A_{t+1}, u, \tau^{*}\right)}{\partial \tau}\right)\right)\right.\right. \\
& +(1-h)\left(w \frac{1-a}{d} U^{\prime}\left(c\left(A_{t+1}, u\right)+\frac{\partial V\left(A_{t+1}, u, \tau^{*}\right)}{\partial \tau}\right)[\right. \\
= & \frac{1-q-h}{(1+r)(1-q)}\left[w \frac{1-a}{d} U^{\prime}\left(c\left(A_{t+1}, u\right)+\frac{\partial V\left(A_{t+1}, u, \tau^{*}\right)}{\partial \tau}\right] .\right.
\end{aligned}
$$

From the above we find that

$$
\frac{\partial V\left(A_{t}, u, \tau^{*}\right)}{\partial \tau}=w \frac{1-a}{d} \sum_{s=1}^{\infty} k^{s} U^{\prime}\left(c\left(A_{t+s}, u\right)>0\right.
$$

where $k \equiv \frac{1-q-h}{(1+r)(1-q)}$ and $U^{\prime}\left(c\left(A_{t+s}, u\right)\right.$ is conditional on the median voter being unemployed from $t+1$ to at least $t+s$.

\section{A.7 Increasing Preferred Tax Rate}

Using (14) we find that $\frac{\partial V\left(A_{t},, \tau_{1}, \tau\right)}{\partial \tau_{1}}=(1+r) r^{-1} e^{-\gamma \frac{r A_{t}}{1+r}} \frac{\partial V\left(., \tau_{1}, \tau\right)}{\partial \tau_{1}}$. Assume that $\tau_{1}=\tau$ is an interior solution to (17). The derivative of $V\left(A_{t}, . ., \tau_{1}, \tau\right)$ with respect to the tax rate in period $t+2$ is then given by

$$
\frac{(1+r) e^{-\gamma} \frac{r A_{t}}{1+r}}{r}\left((1-q) \frac{\partial V\left(e, \tau_{1}, \tau\right)}{\partial \tau_{1}}+q \frac{\partial V\left(u, \tau_{1}, \tau\right)}{\partial \tau_{1}}\right)=\frac{(1+r) e^{-\gamma \frac{r A_{t}}{1+r}}}{r} q \frac{\partial V\left(u, \tau_{1}, \tau\right)}{\partial \tau_{1}}
$$

since $\frac{\partial V\left(e, \tau_{1}, \tau\right)}{\partial \tau_{1}}=0$.

The derivatives $\frac{\partial V\left(., \tau_{1}, \tau\right)}{\partial \tau_{1}}$ are given by

$$
\begin{aligned}
\frac{\partial V\left(e, \tau_{1}, \tau_{2}, \tau\right)}{\partial \tau_{1}} & =\frac{w}{1+r}\left(-(1-q) e^{-\gamma c_{e}}+q \frac{1-a}{d} e^{-\gamma c_{u}}\right) \\
\frac{\partial V\left(u, \tau_{1}, \tau_{2}, \tau\right)}{\partial \tau_{1}} & =\frac{w}{1+r}\left(-h e^{-\gamma c_{e}}+(1-h) q \frac{1-a}{d} e^{-\gamma c_{u}}\right)
\end{aligned}
$$


where $c_{e}$ and $c_{u}$ are determined by $\tau$. Now, we know from results 4 and 5 that $c_{e}>c_{u}$ which implies that $\frac{\partial V\left(u, \tau_{1}, \tau_{2}, \tau\right)}{\partial \tau_{1}}>\frac{\partial V\left(e, \tau_{1}, \tau_{2}, \tau\right)}{\partial \tau_{1}}=0$. Together with the assumption that $1-q>h$, this completes the proof.

\section{A.8 Multiple Stationary States}

Assume that labor market entrants can choose what turnover they will face in the future. Their choice also affects the wage they will get if they become employed. We denote the relation between wages and hiring rates $w(h)$.

We also assume that the separation rate is lower for good matches, i.e., that it falls as the hiring rates decreases. In particular, we assume that the separation rate is proportional to the hiring rate, $q(h)=d h$.

Now, let us define the function

$$
H(\tau) \equiv \arg \max _{h} V(u ; h, q(h), w(h), \tau)
$$

$H(\tau)$ gives the choice of a constant hiring rate maximizing the expected utility of the unemployed. It can be considered a stationary state optimal response function. We require the choice of $h$ to be permanent. This may seem innocuous here; since the environment the individual faces in a stationary state is constant, the optimal search rule is also time invariant. Nevertheless, we will see that this assumption is important for our results.

The economic interpretation of the assumption of a permanent turnover is the following. When entering the labor market, the agents make a decision regarding the degree of specialization of their human capital. The unemployed search for a job matching their individual characteristics. The closer the match, the higher is the productivity of the match and thus the wage they receive, as in, for example, [6]. We can think derivative of the the wage with respect to the distance between the type of job and the type of individual, as the degree of individual specialization. A highly specialized individual gets a high wage but only if she finds a job that closely matches her particular type of skills. The degree of specialization can be assumed to be chosen at an early age and too costly to change later in life. A more specialized individual has more to win by being "picky" when looking for a job. A more specialized individual will get a higher wage and a longer lasting job, but at the price of a longer search time.

We consider our assumption of a choice of constant labor rotation to be a short-cut for a richer model along these lines. ${ }^{15}$

Now let us turn to the employed. We assume that they have set up a political mechanism $T$ determining the tax rate that maximizes their expected future utility. This most preferred tax rate depends on their previous turn-over choice. We can then define

$$
T(h) \equiv \arg \max _{\tau} V(e ; h, q(h), w(h), \tau)
$$

Both $h=H(\tau)$ and $\tau=T(h)$ define mappings between the unemployment insurance rate (determined by $\tau$ ) and the rate of turnover (given by $h$ ). $H(\tau)$ should, intuitively, define a negative relation between unemployment insurance and turnover. The higher the insurance, the less costly it is to wait for a good job, so a high specialization - low turn-over strategy becomes more favorable. This mechanism is explored in Marimon \& Zilibotti [6]. Furthermore, a high tax and insurance rate reduces risk, which also makes the more risky strategy of high specialization more attractive. This is the mechanism explored in section 2.2 .

Now consider $T(h)$. This function is almost identical to functions depicted in Figure 2, the only difference is that the wage may now depend on $h$. We should thus expect $T(h)$ to be decreasing over relevant ranges of $h$.

\footnotetext{
${ }^{15}$ In another paper, we work on a model with a more explicit specification of the search problem in a similar setup.
} 
In Figure 7, we have plotted an example of the mappings defined by $H(\tau)$ and $T(h) .{ }^{16}$ The horizontal axis represents the rate of turnover, indexed by the expected length of an unemployment spell $(1 / h)$, and the vertical axis represents the insurance rate, indexed by the replacement ratio, i.e., unemployment benefits over net wages $(\tau(1-a) /((1-\tau) d)$.

Figure 7: The Unemployed's choice of turnover and the employed's choice of unemployment insurance.

We see that the curves in Figure 7 intersect at two points. One corresponds to a stationary state with high turnover and low insurance, the expected length of an unemployment period is 6 months and unemployment benefits are $4 \%$ of the net wage. We call this the the U.S. stationary state. The other intersection occurs at a low rate of turnover and a high level of unemployment insurance. The expected unemployment period is here 35 months and the insurance gives benefits of $60 \%$ of the net wage. We call this the European stationary state. We have thus established that our model can generate multiple stationary states.

Now let us return to why we assume that the choice of turnover is permanent. The consequence of abandoning this assumption is that the employed in a low turnover job may want to have a low unemployment insurance and if they get unemployed, which only is likely to happen far into the future, then switch to a high turnover strategy. If such a strategy is feasible, it may destroy the low turnover - high insurance stationary state.

\section{References}

[1] Boadway, R. and D. Wildasin, (1989), "Voting Models of Social Security Determination", in Gustavsson, B.A. and N.A. Klevmarken (eds), The Political Economy of Social Security, North-Holland.

[2] Bertola, G., and R. Rogerson, (1996), "Institutions and Labor Reallocation", mimeo.

[3] Gruber, Jonathan, (1994), "The Consumption Smoothing Benefits of Unemployment Insurance", NBER Working Paper No. 4750.

[4] Hall. R. E., (1995), "Lost Jobs", Brookings Papers on Economic Activity, 1:95.

[5] Krusell, Per, Vincenzo Quadrini and José Víctor Ríos Rull, (1996), "Politico-Economic Equilibrium and Economic Growth", Journal of Economic Dynamics and Control, forthcoming.

[6] Marimon, Ramon, and Fabrizio Zilibotti, (1997), "Unemployment vs. mismatch of talents: Reconsidering unemployment benefits", mimeo, Universitat Pompeu Fabra.

[7] Wright, Randall, (1986) "The redistributive Roles of Unemployment Insurance and the Dynamics of Voting". Journal of Public Economics 31.

[8] OECD, (1994), "The OECD Jobs Study, Facts Analysis Strategies", OECD.

\footnotetext{
${ }^{16}$ The wage function $w(h)$ is assumed be $w=1+w_{1}\left(1-e^{-\frac{w_{2}}{h}}\right)$. This function gives a wage of unity as expected unemployment duration approaches zero. As the duration increases, the wage increases at a decreasing rate so that as duration goes to infinity the wage approaches $1+w_{1}$. The curvature of the wage function is determined by $w_{2}$. The parameters used in plotting Figure are $w_{1}=0.09$, $w_{2}=-0.035, a=0.03, r=0.03 /$ year and $\gamma=2$.
} 
[9] OECD, (1995), "Employment Outlook, July 1995", OECD. 
Figure 1
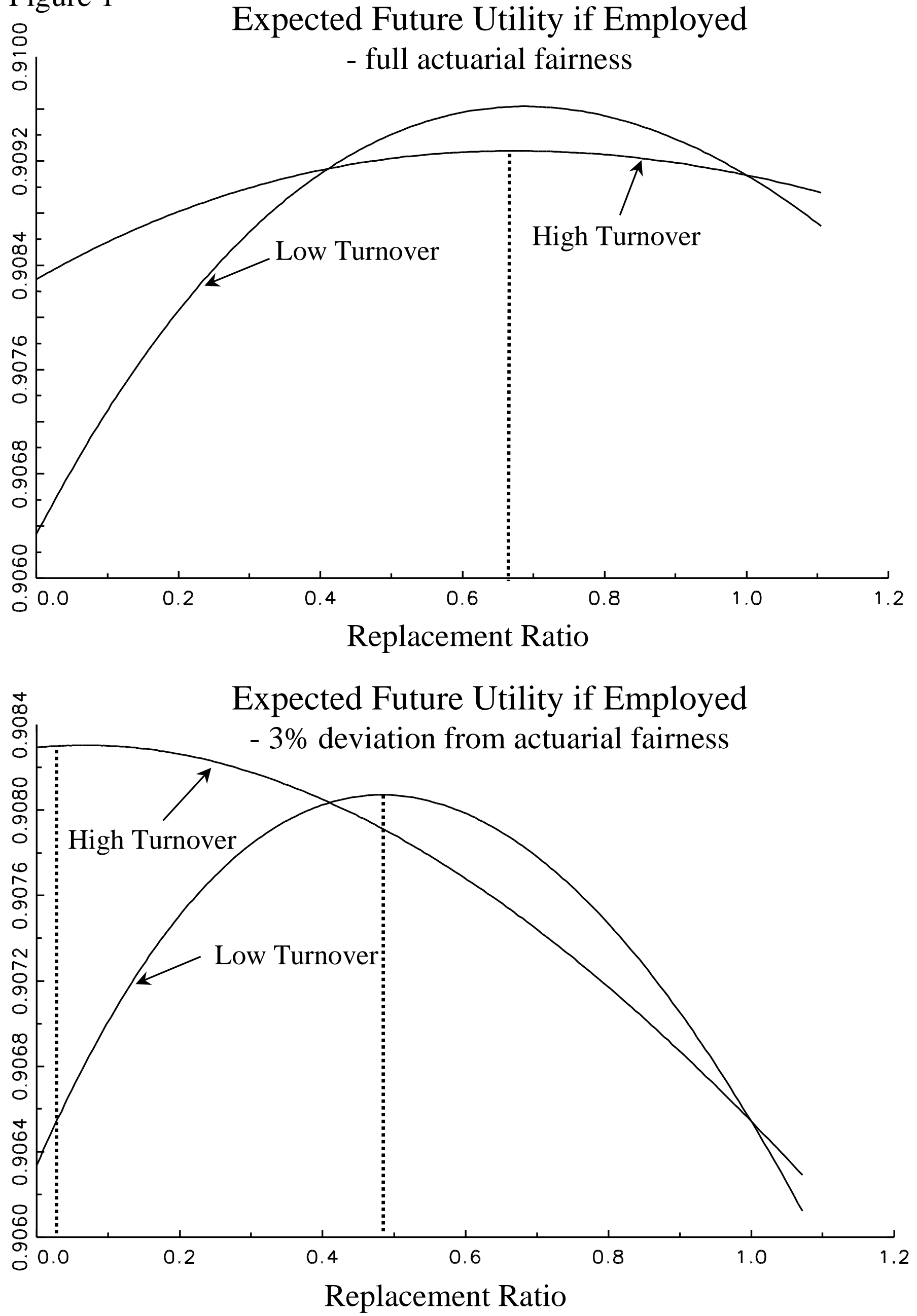


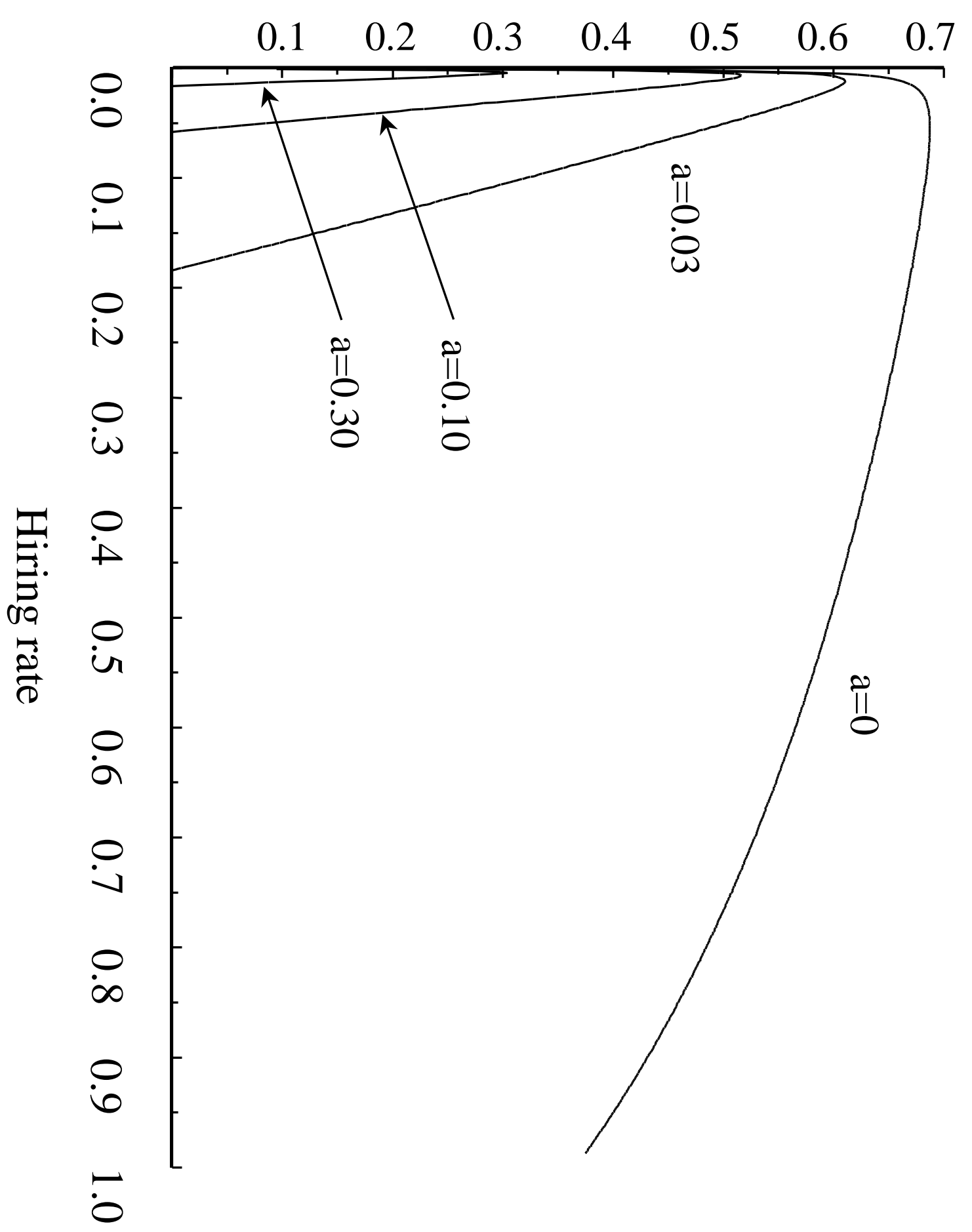

疍 


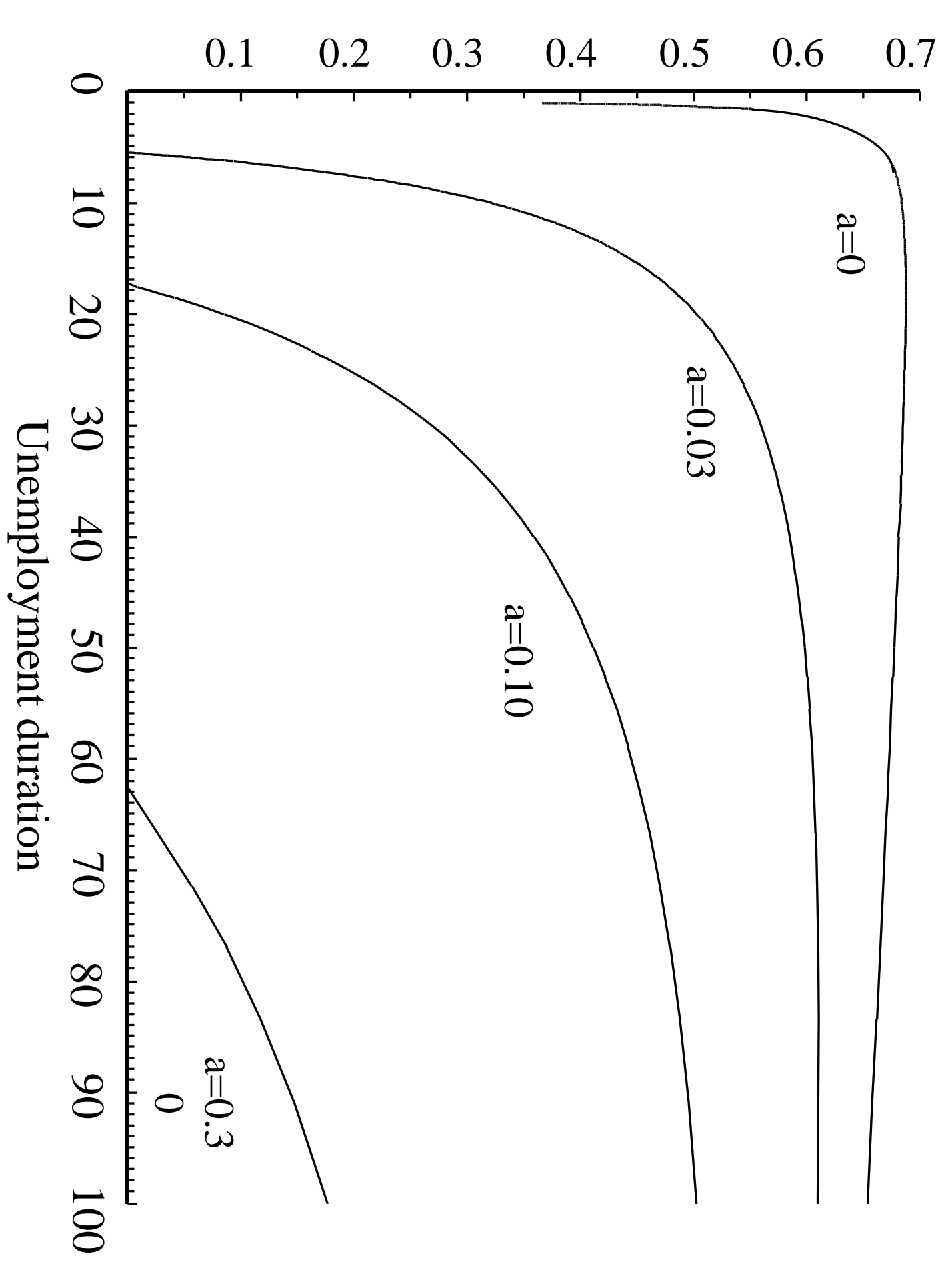

חי̃ 
Figure 3

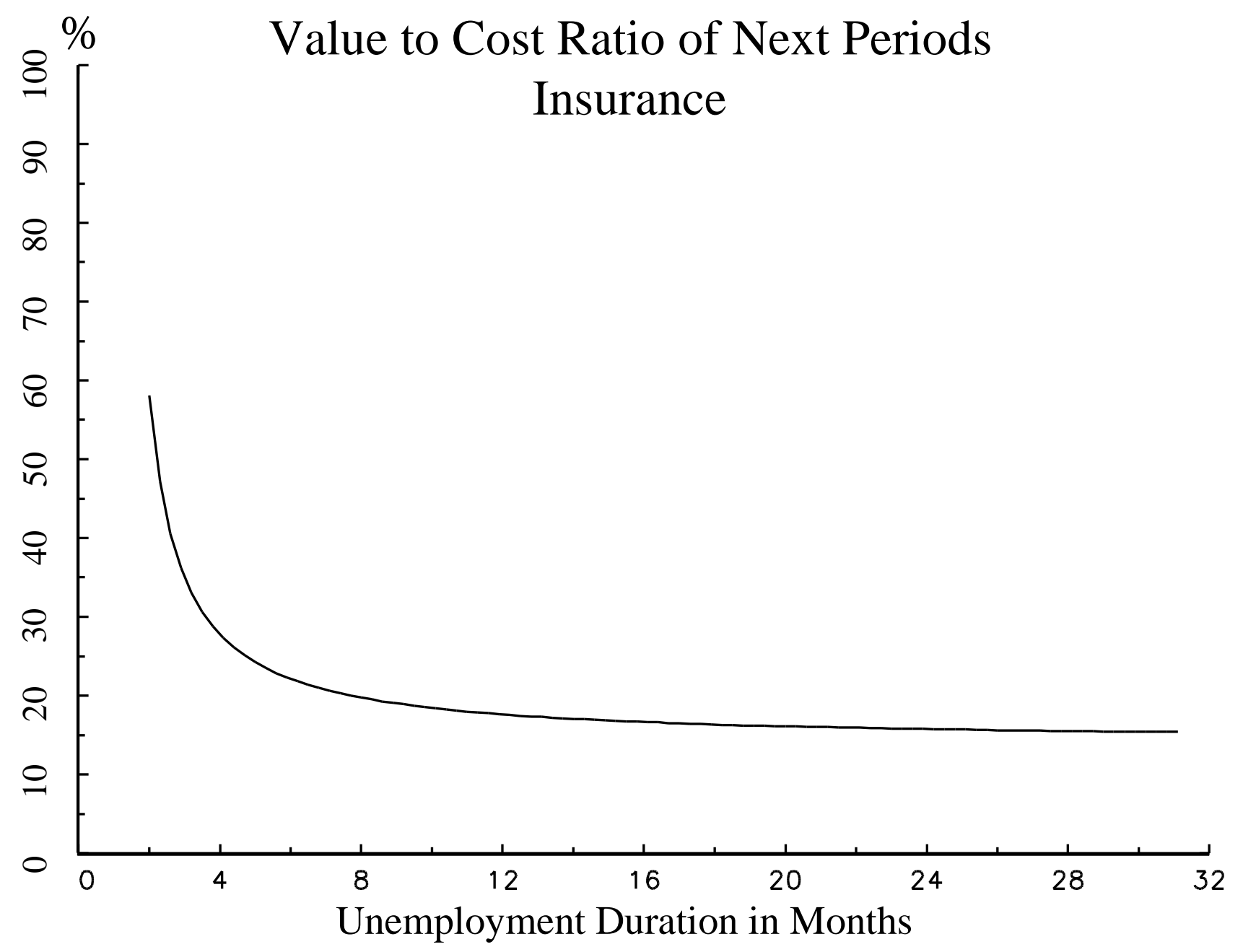


Figure 4

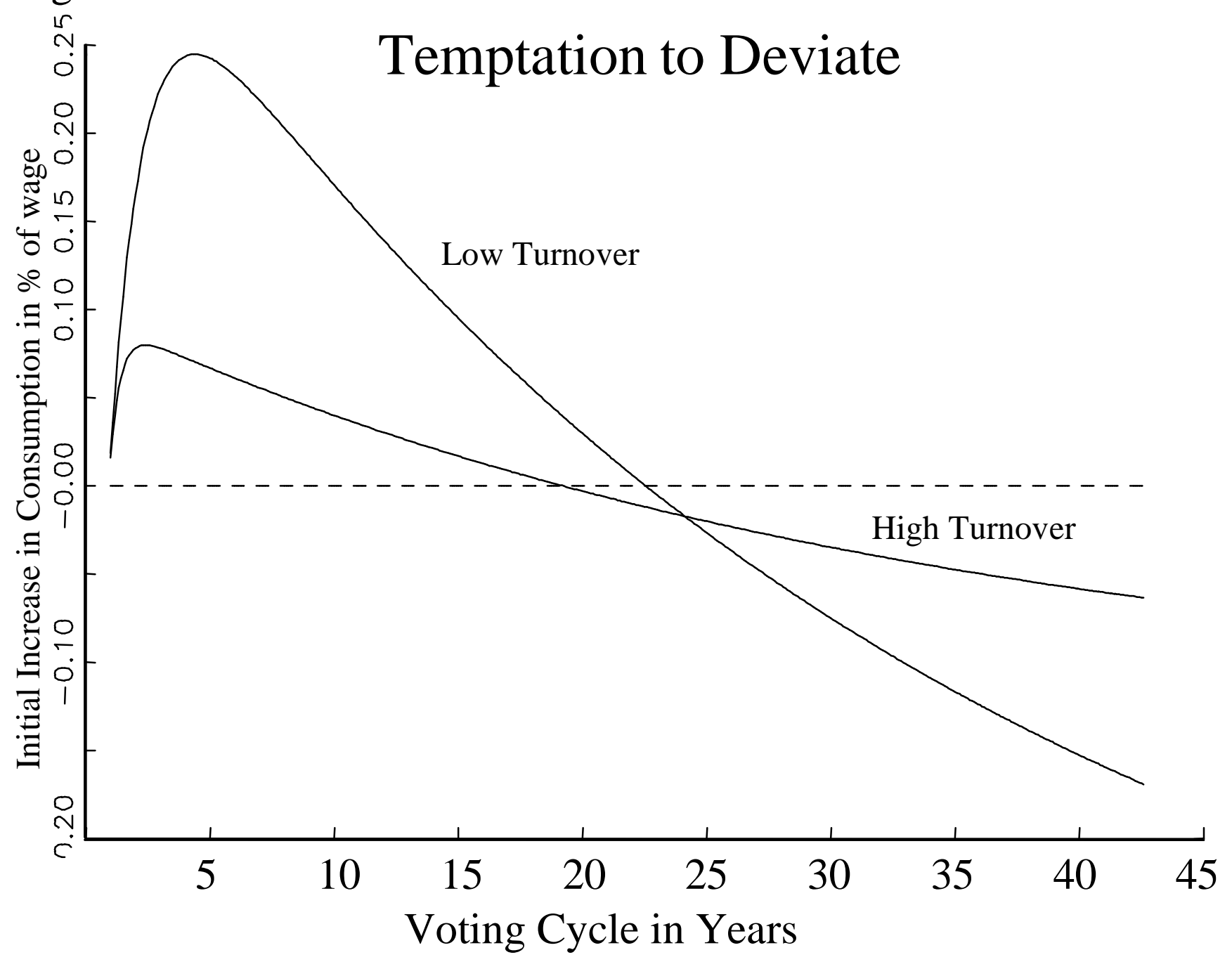


Figure 5

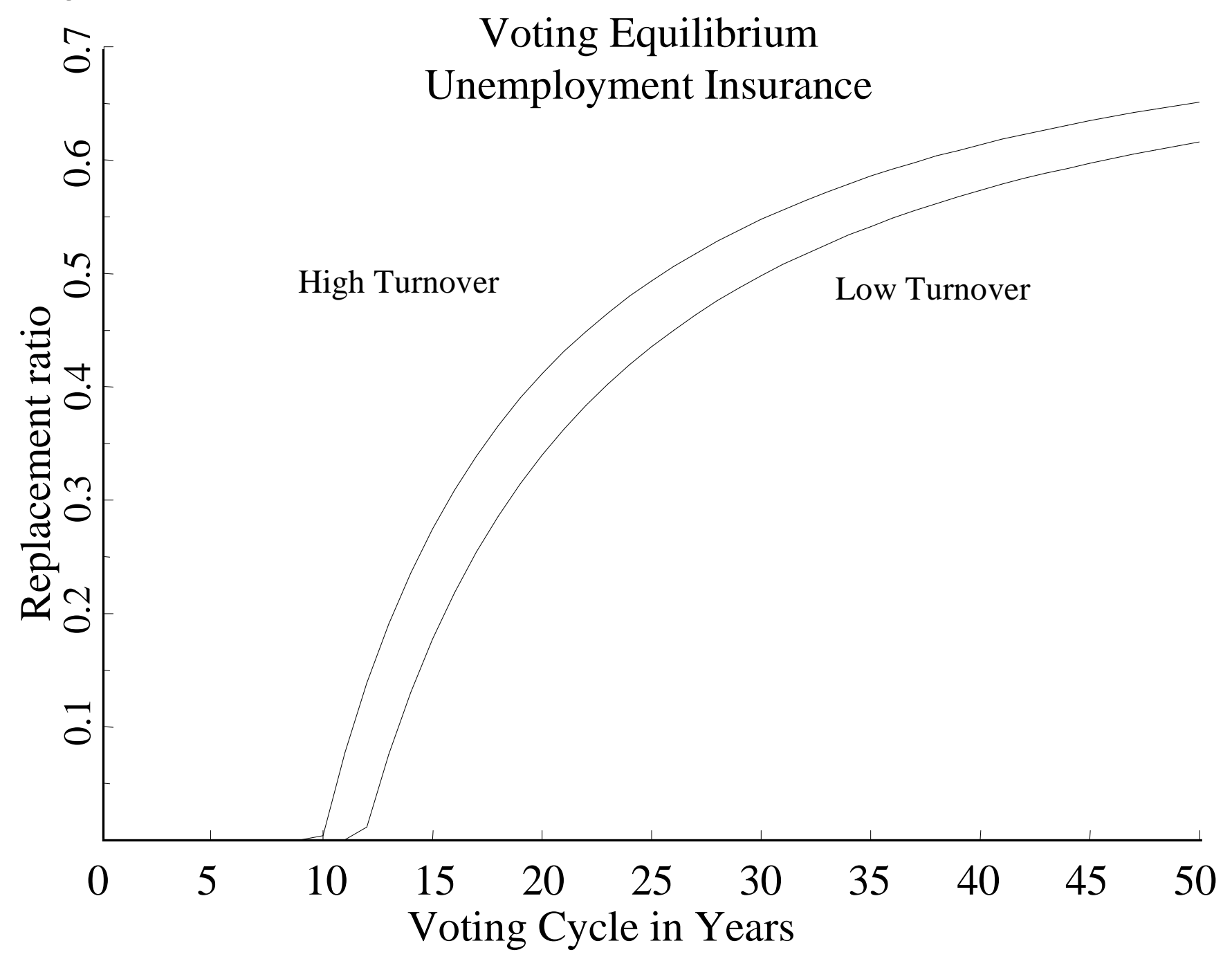


Figure 6

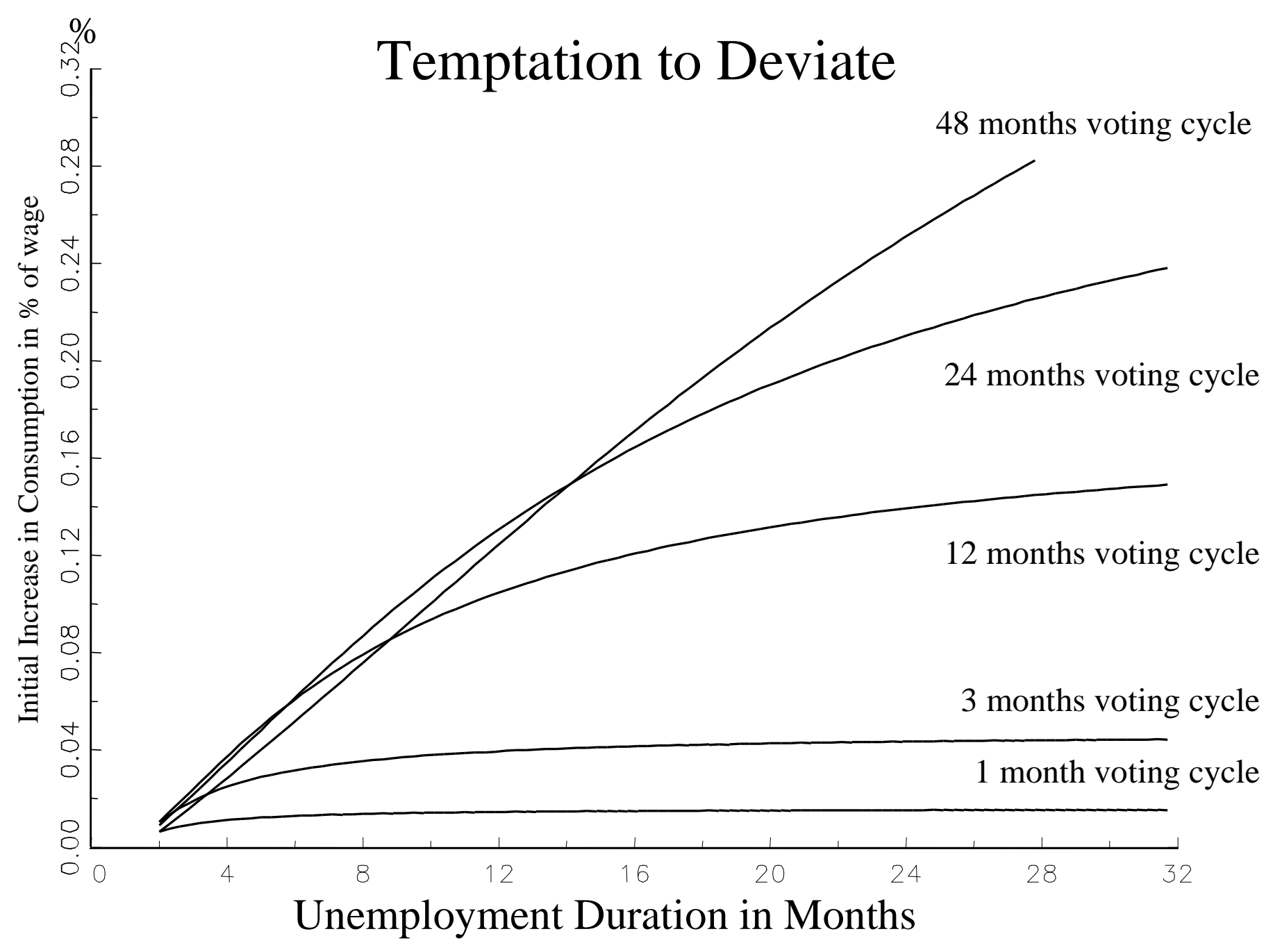


Figure 7

Stationary State Optimal Response Functions

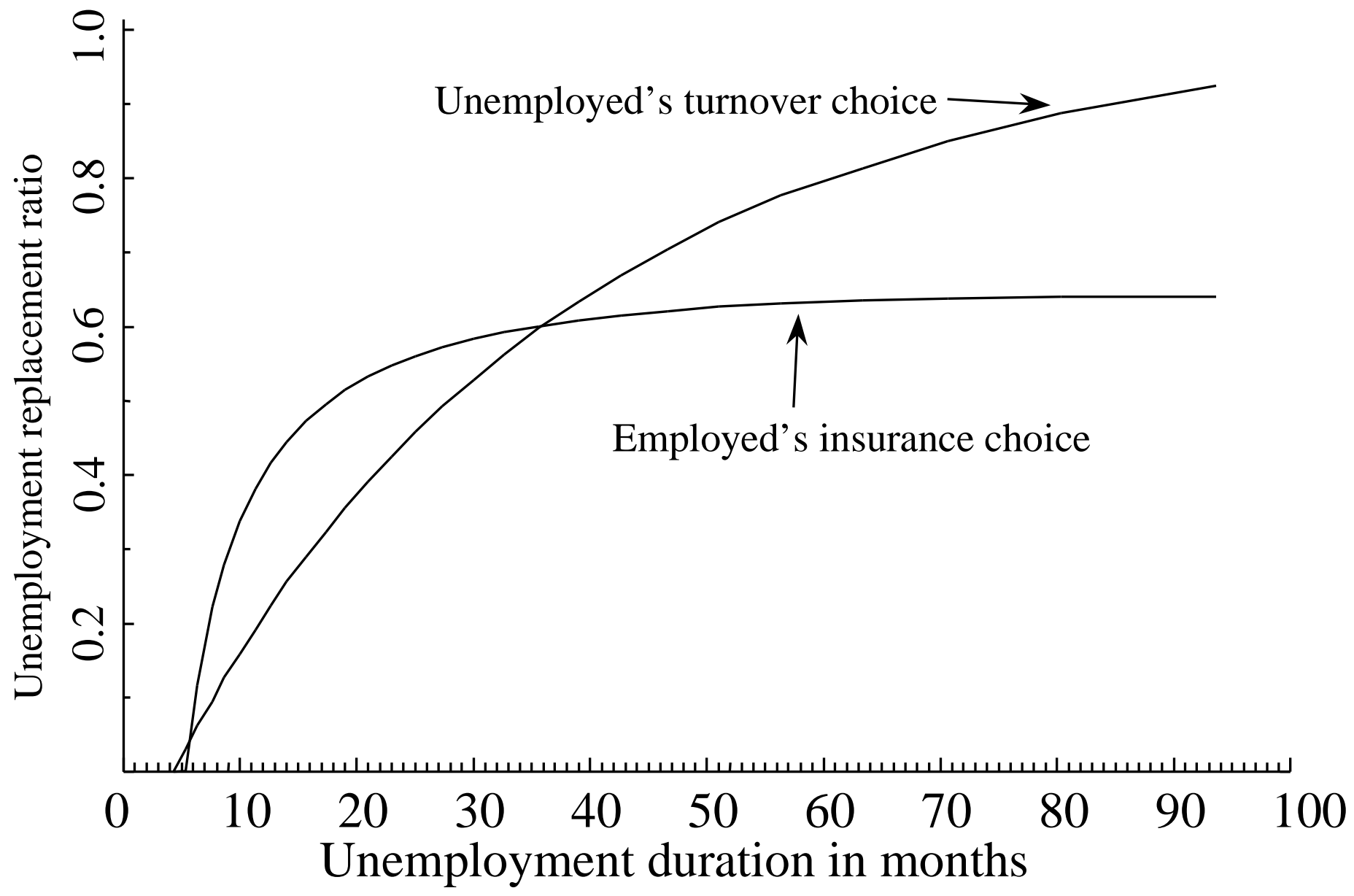

